\title{
Synthesis of a Pyrene-Derived Schiff Base and Its Selective Fluorescent Enhancement by Zinc and Aluminum Ions
}

\author{
Ping-Feng Hsu, Yun Chen* \\ Department of Chemical Engineering, National Cheng Kung University, Taiwan \\ Email: *yunchen@mail.ncku.edu.tw
}

How to cite this paper: Hsu, P.-F. and Chen, Y. (2018) Synthesis of a PyreneDerived Schiff Base and Its Selective Fluorescent Enhancement by Zinc and Aluminum Ions. International Journal of Organic Chemistry, 8, 207-228.

https://doi.org/10.4236/ijoc.2018.82016

Received: January 15, 2018

Accepted: June 9, 2018

Published: June 12, 2018

Copyright ( 92018 by authors and Scientific Research Publishing Inc. This work is licensed under the Creative Commons Attribution International License (CC BY 4.0).

http://creativecommons.org/licenses/by/4.0/

\begin{abstract}
An efficient pyrene-Schiff base fluorescent sensor PySb was synthesized and evaluated for its fluorescence response to metal ions. Sensor PySb exhibits an "off-on-type" mode with high selectivity to $\mathrm{Zn}^{2+}$ and $\mathrm{Al}^{3+}$ in ethanol (470 nm) and in dimethyl sulfoxide $(458 \mathrm{~nm})$ respectively. The originally non-fluorescent PySb, due to photo-induced electron transfer (PET) from imine moiety, is turned on after binding with the cations. The stoichiometric ratio between PySb and $\mathrm{Zn}^{2+}$ is 1:2; moreover, the limit of detection (LOD) and bonding constant were $2.39 \times 10^{-8} \mathrm{M}$ and $2 \times 10^{9} \mathrm{M}^{-1}$ respectively, as obtained from titration experiments.
\end{abstract}

\section{Keywords}

Fluorescent Sensor, Pyrene, Schiff Base, Photo-Induced Electron Transfer (PET), Limit of Detection (LOD)

\section{Introduction}

Zinc ion has been known as the second most abundant transition metal ion in human body. While most zinc ions are tightly bound in proteins, a small amount of free $\mathrm{Zn}^{2+}$ ions is presented in various human tissues [1] [2] [3] [4] [5]. Some neurologic diseases are found to associate with free $\mathrm{Zn}^{2+}$. For instance, the abnormal accumulation of $\mathrm{Zn}^{2+}$ is found in patients with Alzheimer's disease [6]. Moreover, $\mathrm{Zn}^{2+}$ plays an important role in the regulation of apoptosis (programmed cell death) [7]. Aluminum is the third most abundant element in earth's crust, and it is the most abundant metal on earth. High concentration of aluminum in soils may lead to environmental issues such as acid soils [8] [9]. In human body, aluminum is known to associate with the development of Alzhei- 
mer's disease and Parkinson's disease [10] [11] [12]. Therefore, the development of $\mathrm{Zn}^{2+}$ and $\mathrm{Al}^{3+}$ sensors for environmental and biological monitoring is critical. Compare to traditional detection methods such as atomic absorption spectroscopy, electrochemical sensor, and inductively coupled plasma atomic emission spectrometry, fluorescent sensors have become a popular tool for the detection of metal ions due to their simple operating processes [13] [14] [15].

Schiff base moieties have been extensively applied as ionophores in fluorescent sensors due to their ability to form coordination complexes with metal ions [16] [17] [18]. Some fluorescent sensors based on Schiff base moieties have been synthesized to detect $\mathrm{Zn}^{2+}$ [19] [20] [21] or $\mathrm{Al}^{3+}$ [22] [23] [24]. However, only a few sensors demonstrated fluorescence responses toward multiple metal ions. Besides, some of these sensors exhibited responses toward multiple metal ions simultaneously [25] [26]. Therefore, it is highly desirable to synthesize fluorescent sensors with specific responses toward multiple metal ions.

In this work, a novel fluorescent sensor PySb was synthesized and characterized. Fluorescent pyrene moiety was selected as fluorophore to enhance sensitivity. 2-amino-2-(hydroxymethyl)propane-1,3-diol was chosen as part of binding moiety. By forming imine via reaction with 2-hydroxybenzaldehyde, the three alcoholic $-\mathrm{OH}$ along with phenolic - $\mathrm{OH}$ should be able to interact with multiple metal ions [27] [28]. Accordingly, specific responses toward $\mathrm{Zn}^{2+}$ and $\mathrm{Al}^{3+}$ can be expected.

\section{Experimental}

\subsection{Materials and Measurements}

All the reagents and solvents were purchased from commercial sources and were used without further purification. 4-(2-hydroxyethyl)-1-piperazineethanesulfonic acid) (HEPES) was dissolved in water $\left(2.5 \times 10^{-4} \mathrm{M}\right)$ which was used as buffer solution. Nitrate salts of $\mathrm{Na}^{+}, \mathrm{K}^{+}, \mathrm{Ca}^{2+}, \mathrm{Cu}^{2+}, \mathrm{Ni}^{2+}, \mathrm{Co}^{2+}, \mathrm{Zn}^{2+}, \mathrm{Pb}^{2+}, \mathrm{Fe}^{3+}, \mathrm{Cr}^{3+}$ and $\mathrm{Al}^{3+}$ were dissolved in the $\mathrm{HEPES}_{(\mathrm{aq})}$ buffer to prepare their stock solutions $\left(10^{-2}\right.$ M). PySb was dissolved in ethanol, DMF, or DMSO; the concentration was $2 \times$ $10^{-5} \mathrm{M} .{ }^{1} \mathrm{H}$ NMR spectra with the chemical shifts reported in ppm were recorded on a Bruker AMX-600 MHz spectrometer, using tetramethylsilane (TMS) as an internal standard. Elemental analysis (EA) of carbon, hydrogen, and nitrogen were measured on a Heraus CHN-Rapid elemental analyzer. The UV-Vis absorption spectra were recorded on a Jasco V-550 spectrophotometer using a quartz cuvette (path length $=1 \mathrm{~cm}$ ). Photoluminescence $(\mathrm{PL})$ spectra were recorded on a fluorescence spectrophotometer (Hitachi F-4500) in mixtures of water with appropriate organic solvents.

\subsection{Synthesis of PySb (Scheme 1)}

To a sodium carbonate solution $(0.6 \mathrm{M}, 2.8 \mathrm{ml})$ in 50 - $\mathrm{mL}$ glass reactor was added with 5-bromo-2-hydroxybenzaldehyde (1: $0.264 \mathrm{~g}, 1.32 \mathrm{mmol}$ ), 2,7-bis(4,4,5, 5-tetramethyl-1,3,2-dioxaborolan-2-yl)pyrene (2:0.2 g, $0.44 \mathrm{mmol})$, and tri-tert- 

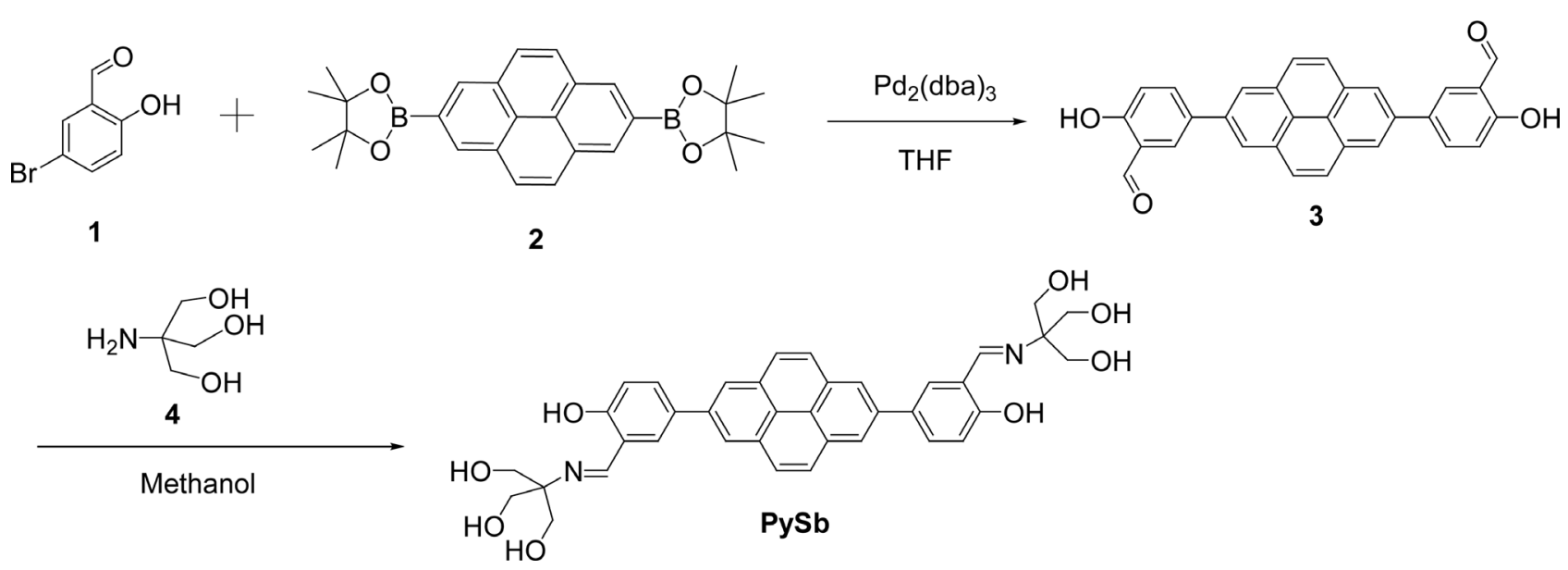

Scheme 1. Synthesis of fluorescent sensor PySb.

butylphosphonium tetrafluoroborate $(0.032 \mathrm{~g}, 0.11 \mathrm{mmol})$.

Tris(dibenzylideneacetone)dipalladium $(0)\left(\mathrm{Pd}_{2}(\mathrm{dba})_{3}: 57 \mathrm{mg}, 0.06 \mathrm{mmol}\right)$ was dissolved in THF $(18 \mathrm{ml})$ and added into the reactor by a syringe. The mixture was degassed by the freeze-pump-thaw cycle for three times. Next, the mixture was stirred at $65^{\circ} \mathrm{C}$ for two days; then it was poured into water and extracted with dichloromethane. The combined organic layer was concentrated under reduced pressure, poured into $n$-hexane to obtain precipitate as crude product. The crude product was purified by flash column chromatography (eluent: dichloromethane) to afford 5,5'-(pyrene-2,7-diyl)bis(2-hydroxybenzaldehyde) (3) (yield: $0.11 \mathrm{~g}, 56.4 \%) .{ }^{1} \mathrm{H}$ NMR (600 MHz, DMSO-d, TMS, $25^{\circ} \mathrm{C}$ ): $\delta 10.80-$ 11.03 (s, 2H, -CHO), 10.47 - 10.36 (s, 2H, -OH), 8.62 - 8.57 (s, 4H, Ar-H), 8.31 8.26 (s, 6H,Ar-H), 8.23 - 8.13 (d, 2H, Ar-H), 7.28 - 7.20 (d, 2H, Ar-H).

A mixture of $3(0.15 \mathrm{~g}, 0.39 \mathrm{mmol}), 2$-amino-2-(hydroxymethyl)propane1,3-diol (4:0.41 g, $3.9 \mathrm{mmol})$ and methanol $(150 \mathrm{ml})$ was stirred at $65^{\circ} \mathrm{C}$ for two days. Methanol was evaporated by a rotavapor. The crude product was washed by water and acetone several times to obtain PySb (yield: $0.20 \mathrm{~g}, 90.8 \%$ ). ${ }^{1} \mathrm{H}$ NMR (600 MHz, DMSO-d ${ }_{6}$, TMS, $\left.25^{\circ} \mathrm{C}\right): \delta 14.79-14.64$ (s, 2H, phenolic OH), $8.80-8.71$ (s, 2H, CNH), 8.63 - 8.55 (s, 4H, Ar-H), 8.28 - 8.19 (s, 4H, Ar-H), 8.17 - 8.09 (s, 2H, Ar-H), 8.03 - 7.95 (d, 2H, Ar-H), 7.01 - 6.93 (d, 2H, Ar-H), 4.90 $4.78(\mathrm{~s}, 6 \mathrm{H}, \mathrm{OH}), 3.71-3.63\left(\mathrm{~d}, 12 \mathrm{H}, \mathrm{CH}_{2}\right)$. Anal. Calcd. for $\mathrm{C}_{38} \mathrm{H}_{36} \mathrm{~N}_{2} \mathrm{O}_{8}$ (\%): $\mathrm{C}$, 70.36; H, 5.59; N, 4.32. Found: C, 69.47; H, 5.56; N, 4.20.

\section{Results and Discussion}

\subsection{Synthesis of Fluorescent Sensor PySb}

The new fluorescent sensor PySb was synthesized in two steps as shown in Scheme 1. First, the bis(2-hydroxybenzaldehyde) derivative (3) of pyrene was synthesized from 5-bromo-2-hydroxybenzaldehyde (1) and diboronate derivative of pyrene (2) via the Suzuki coupling reaction (Figure S1, Supplementary Material). It was further condensed with 2-amino-2-(hydroxymethyl)propane1,3-diol (4) via imine formation to obtain the fluorescent sensor PySb. The PySb 


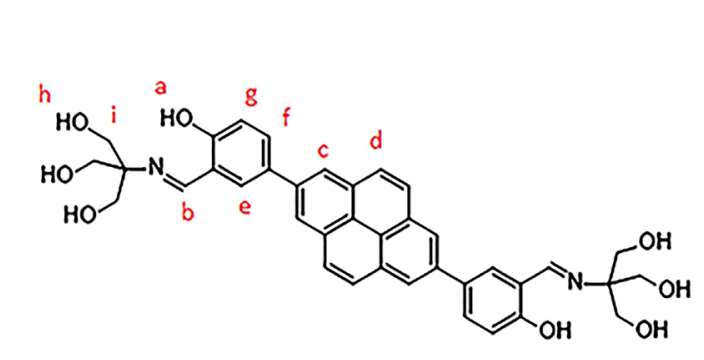

was characterized by ${ }^{1} \mathrm{H}$ NMR spectrum, mass spectra, and elemental analysis. The ${ }^{1} \mathrm{H}$ NMR spectrum of PySb is demonstrated in Figure 1, in which the respective protons can be readily assigned due to its chemically symmetric structure. The chemical shifts at $3.71-3.63 \mathrm{ppm}$ (i) are assigned to the protons of methylene protons next to alcoholic $-\mathrm{OH}$, whereas those at $4.90-4.78 \mathrm{ppm}(\mathrm{h})$ are assigned to the protons of alcoholic $-\mathrm{OH}$. The chemical shifts at $7.01-6.93$ ppm (g), 8.03 - 7.95 ppm (f), and 8.17 - 8.09 ppm (e) have been assigned to the protons on benzene rings. The chemical shifts at $8.28-8.19 \mathrm{ppm}$ (d) and 8.63 $8.55 \mathrm{ppm}$ (c) are assigned to the protons on pyrene core. Finally, the chemical shifts at $8.80-8.71 \mathrm{ppm}$ (b) are arisen from the protons on $\mathrm{C}=\mathrm{N}$ bond. The chemical shifts at $14.79-14.64 \mathrm{ppm}$ (a) are assigned to phenolic protons. The mass spectrum of PySb was measured by positive ion mode $(\mathrm{M}+\mathrm{H})$ (Figure $\mathrm{S} 2$ ). The average neutral mass of PySb is 648.70 (Figure S3). Setting $\mathrm{m} / \mathrm{z}$ value of 649.25 to $100.00 \%$, the corresponding $\mathrm{m} / \mathrm{z}$ value of $650.25,651.26,652.26$, and 653.26 were $42.57 \%, 10.48 \%, 1.89 \%$, and $0.26 \%$, respectively.

\subsection{Photophysical Properties in Ethanol Buffer Solutions}

The absorption spectra of PySb with various metal ions in ethanol buffer solutions
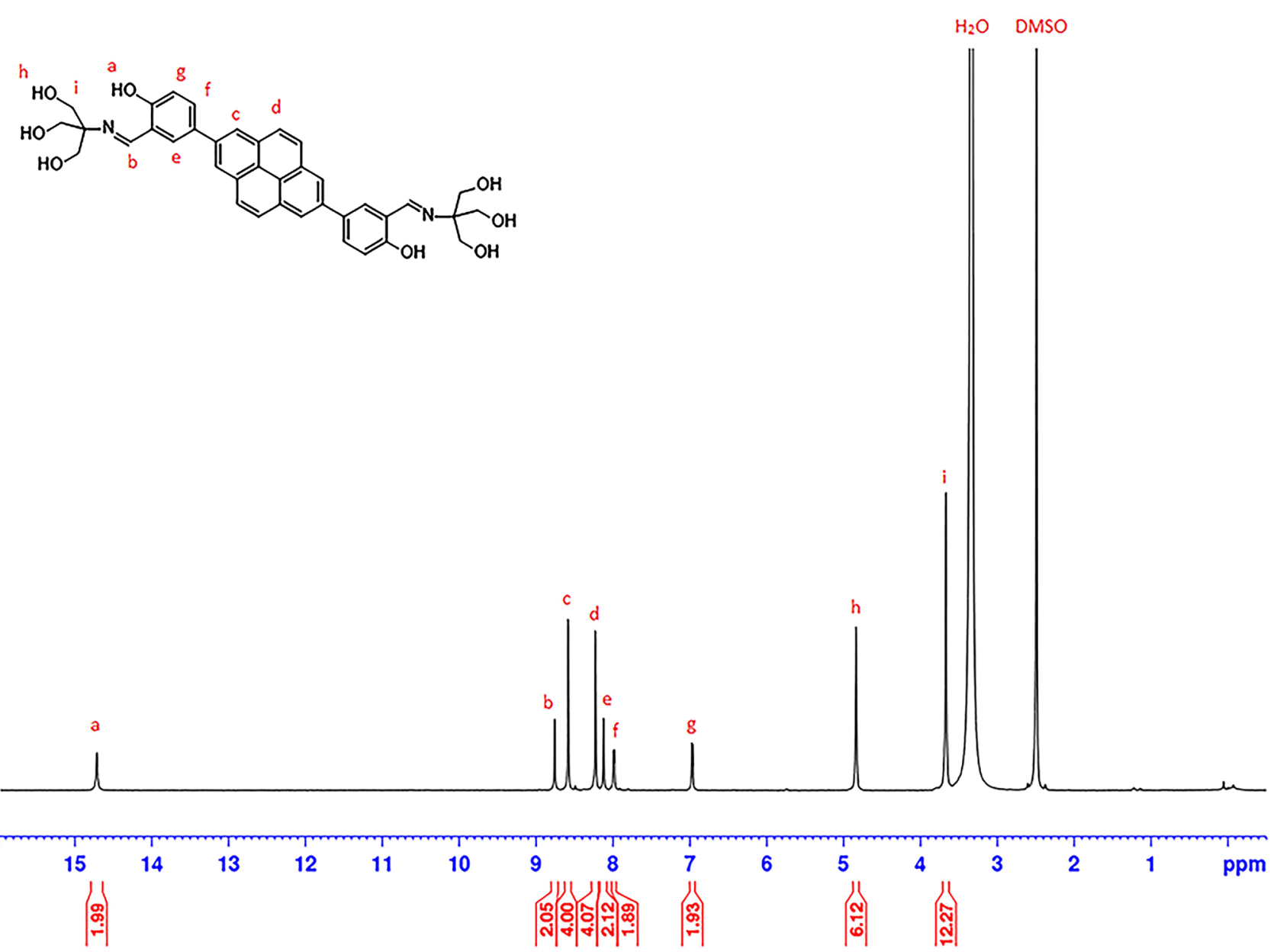

Figure 1. ${ }^{1} \mathrm{H}$ NMR spectrum of PySb in DMSO- $\mathrm{d}_{6}$. 
are depicted in Figure 2. The absorption band at $306 \mathrm{~nm}$ is attributed to the $\pi-\pi^{*}$ transitions of pyrene core [29]. Upon addition of $\mathrm{Na}^{+}, \mathrm{K}^{+}, \mathrm{Ca}^{2+}$, the absorption of $\mathrm{PySb}$ remains nearly unchanged, indicating that $\mathrm{PySb}$ does not interact with these ions. On the other hand, the absorption intensities increased with little red or blue shifts $\left(1-10 \mathrm{~nm}\right.$ ) when $\mathrm{Cu}^{2+}, \mathrm{Ni}^{2+}, \mathrm{Co}^{2+}, \mathrm{Zn}^{2+}, \mathrm{Pb}^{2+}, \mathrm{Fe}^{3+}, \mathrm{Cr}^{3+}$, or $\mathrm{Al}^{3+}$ were added. This suggests that PySb might have interaction with these ions.

PySb itself exhibits very weak fluorescence in ethanol buffer solution (Figure 3). The fluorescence quenching can be explained by the photo-induced electron-transfer (PET) mechanism [30] [31] as illustrated in Figure 4. The fluorescent relaxation of photo-excited electron from pyrene core is forbidden, because the HOMO has been fully filled by obtaining an electron from high-lying HOMO of the terminal 2-iminophenol groups. Upon addition of various metal ions, only $\mathrm{Zn}^{2+}$ ion caused a significant enhancement of fluorescence intensity (51 times compared to free PySb, $\lambda_{\mathrm{em}}=470 \mathrm{~nm}$ ). The enhanced sky-blue fluorescence can be clearly observed by naked eyes (Figure 5 ). The result shows that PySb can be applied as an efficient $\mathrm{Zn}^{2+}$ sensor in ethanol solution.

The binding stoichiometry between PySb and $\mathrm{Zn}^{2+}$ was determined by the Job plot. By plotting the fluorescence intensities versus the molar fraction of $\mathrm{Zn}^{2+}$, two regression lines are obtained and they intersect at about 0.66 (Figure 6), indicating 1:2 stoichiometric ratio between $\mathrm{PySb}$ and $\mathrm{Zn}^{2+}$. In other words, each terminal Schiff base moiety in PySb chelates with one $\mathrm{Zn}^{2+}$.

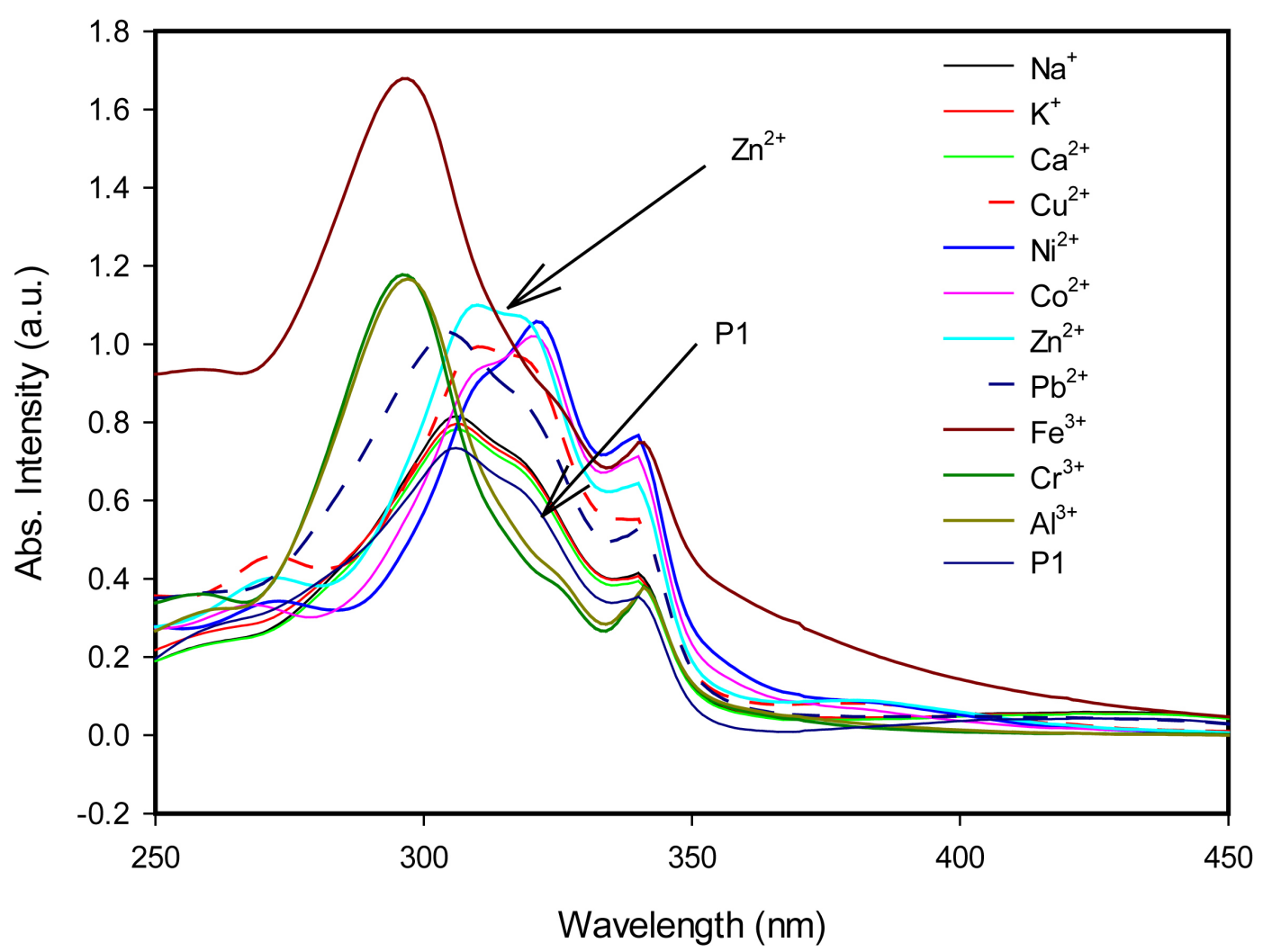

Figure 2. UV-Vis spectra of PySb $\left(10^{-5} \mathrm{M}\right)$ with various metal ions $\left(2 \times 10^{-4} \mathrm{M}\right)$ in HEPES buffer solution (Ethanol/ $\left.\mathrm{H}_{2} \mathrm{O}=9 / 1, \mathrm{v} / \mathrm{v}\right)$. 


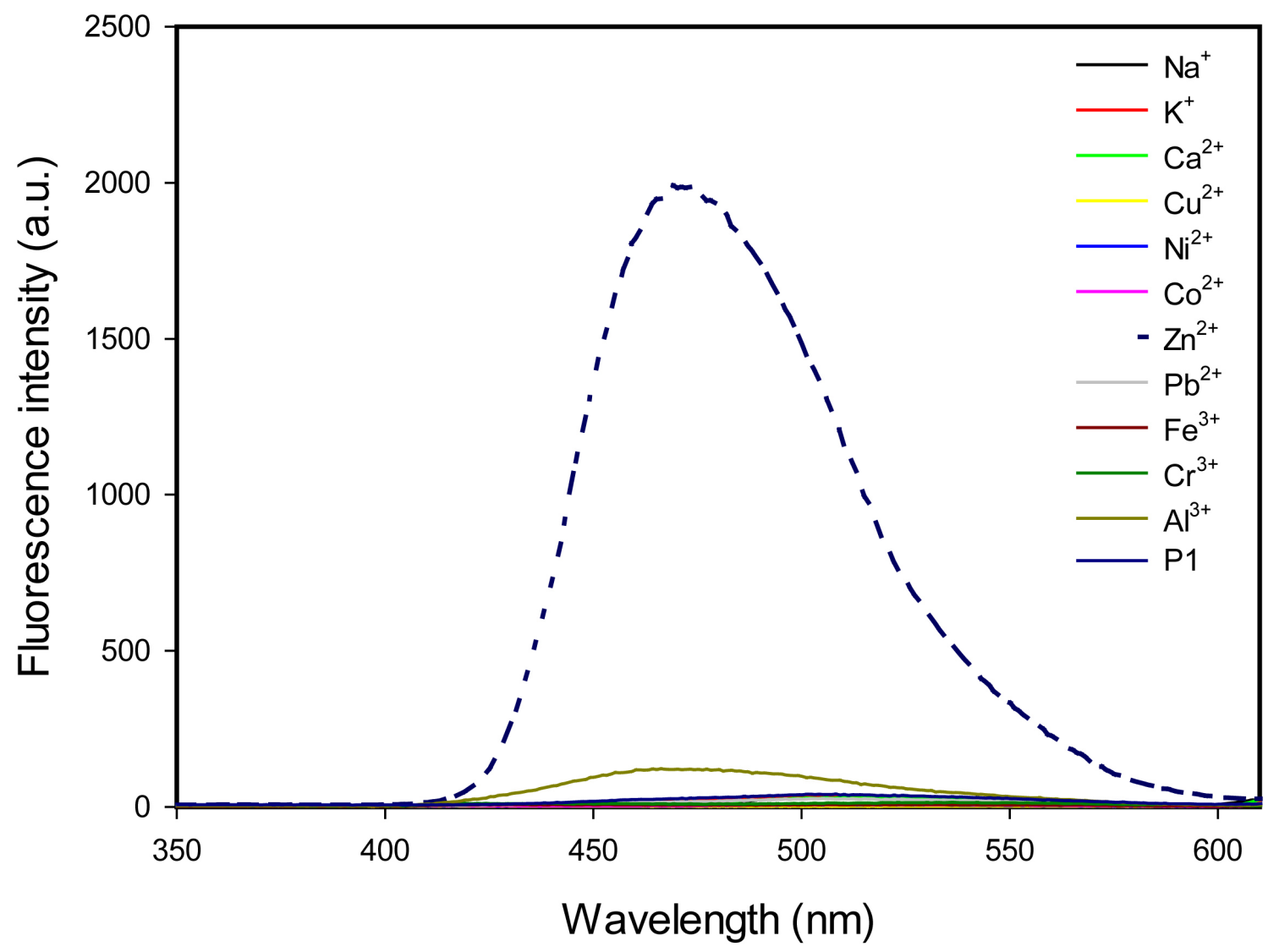

Figure 3. Fluorescence spectra of PySb $\left(10^{-5} \mathrm{M}\right)$ with various metal ions $\left(2 \times 10^{-4} \mathrm{M}\right)$ in HEPES buffer solutions (Ethanol/ $\mathrm{H}_{2} \mathrm{O}=9 / 1, \mathrm{v} / \mathrm{v}$ ), $\lambda_{\mathrm{ex}}=309 \mathrm{~nm}$.<smiles>OCC(CO)(CO)N=Cc1cc(-c2cc3ccc4cc(-c5ccc(O)c(C=NC(CO)(CO)CO)c5)cc5ccc(c2)c3c45)ccc1O</smiles>

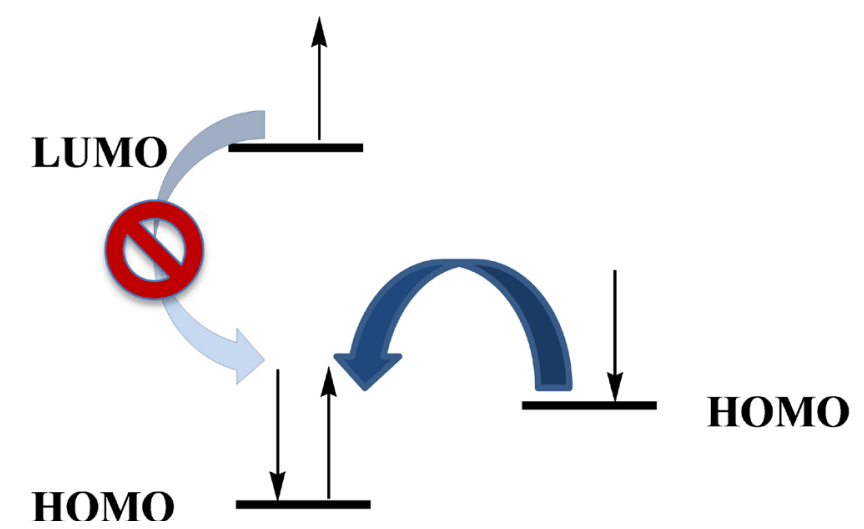

Figure 4. PET mechanism of PySb. 


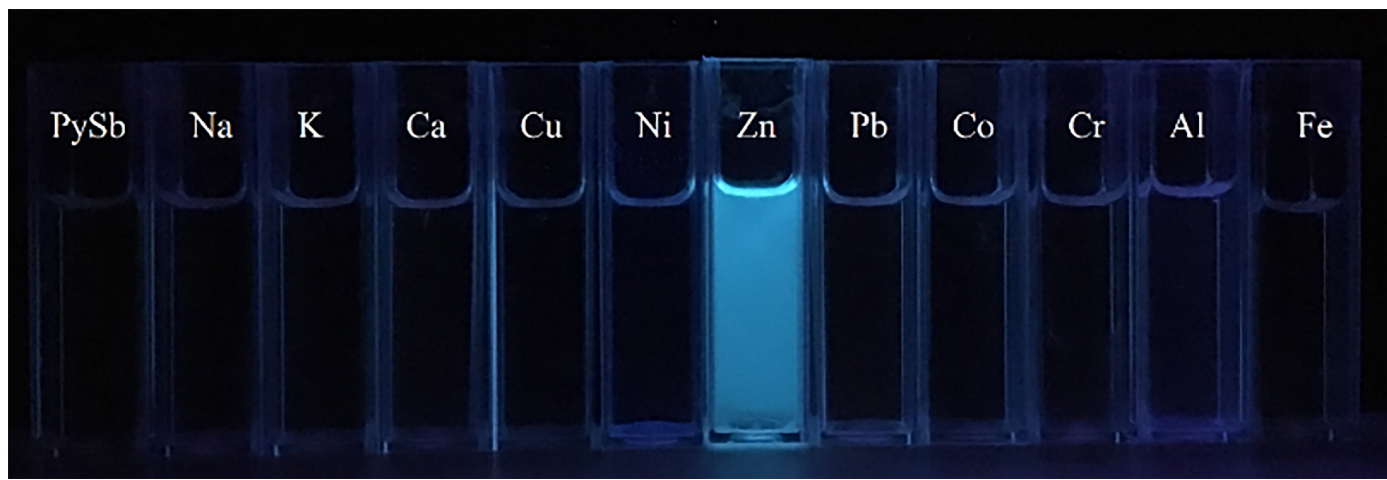

Figure 5. Photographs of PySb $\left(10^{-5} \mathrm{M}\right)$ with various metal ions $\left(2 \times 10^{-4} \mathrm{M}\right)$ in HEPES buffer solutions (Ethanol/ $\mathrm{H}_{2} \mathrm{O}=9 / 1, \mathrm{v} / \mathrm{v}$ ) under UV-light.

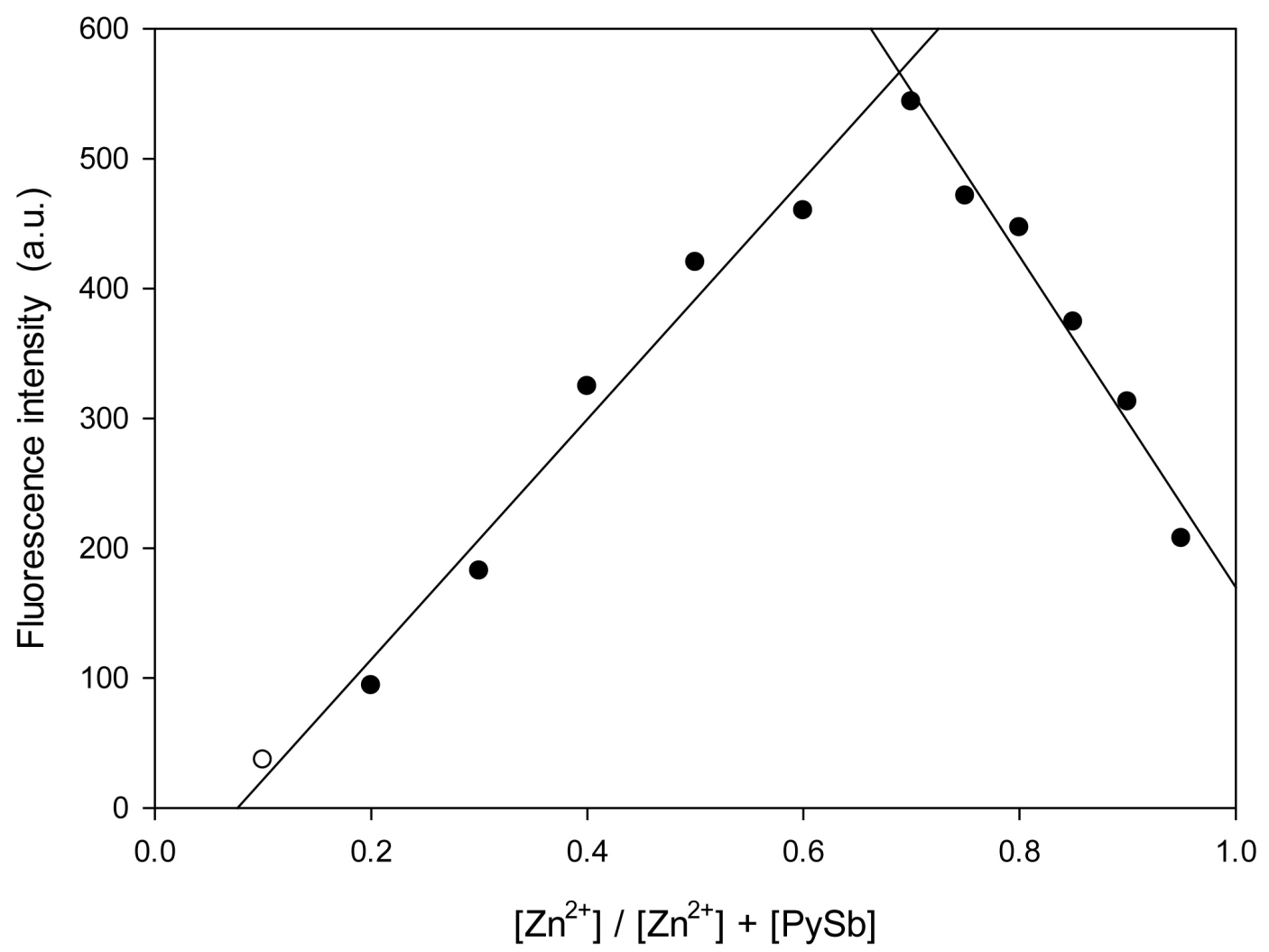

Figure 6. Job plot of PySb and $\mathrm{Zn}^{2+}$ in HEPES buffer solutions (Ethanol/ $\mathrm{H}_{2} \mathrm{O}=9 / 1$, v/v). The total concentration of PySb and $\mathrm{Zn}^{2+}$ was $10^{-5} \mathrm{M}\left(\lambda_{\mathrm{ex}}=309 \mathrm{~nm}, \lambda_{\mathrm{em}}=470 \mathrm{~nm}\right)$.

To further investigate the sensitivity of this fluorescence enhancement, PL spectra of PySb were measured with increasing amount of $\mathrm{Zn}^{2+}$ (from 0.1 to 20 equivalents). As depicted in Figure 7, the fluorescence intensity increases gradually with increasing $\mathrm{Zn}^{2+}$ concentration and reaches the asymptotic value at approximately 12 equivalents of $\mathrm{Zn}^{2+}$ ion. The binding constant $\left(K_{\mathrm{a}}\right)$ of PySb was evaluated from titration data as $2 \times 10^{9} \mathrm{M}^{-1}$ using the Benesi-Hildebrand plot. Moreover, the limit of detection (LOD) was $2.39 \times 10^{-8} \mathrm{M}$ using the equation LOD $=3 \sigma / m$, where $\sigma$ and $m$ represent the standard deviation (0.558) of blank solutions and the slope $\left(7 \times 10^{7}\right)$ of fluorescence intensity versus $\mathrm{Zn}^{2+}$ concentra- 
tion plot respectively (Figure S5).

For real-time application, it is important to evaluate the interference from other metal ions. As shown in Figure 8, only $\mathrm{Na}^{+}, \mathrm{K}^{+}$, and $\mathrm{Ca}^{2+}$ show no interference against $\mathrm{Zn}^{2+}$ sensing. This is coincident with the above-mentioned spectral observation of $\mathrm{PySb}$, i.e., no obvious spectral change in the presence of these three ions. However, the fluorescence intensities of PySb were partially diminished by $\mathrm{Ni}^{2+}, \mathrm{Co}^{2+}$, and $\mathrm{Pb}^{2+}$. Moreover, the fluorescence intensities were dramatically debilitated in the presence of $\mathrm{Fe}^{3+}, \mathrm{Cr}^{3+}$, or $\mathrm{Al}^{3+}$, indicating that these ions bind strongly with PySb to quench the fluorescence. Finally, $\mathrm{Cu}^{2+}$ was the only metal ion that completely quenched the fluorescence. This quenching phenomenon is commonly seen in many fluorescent sensors owning to the
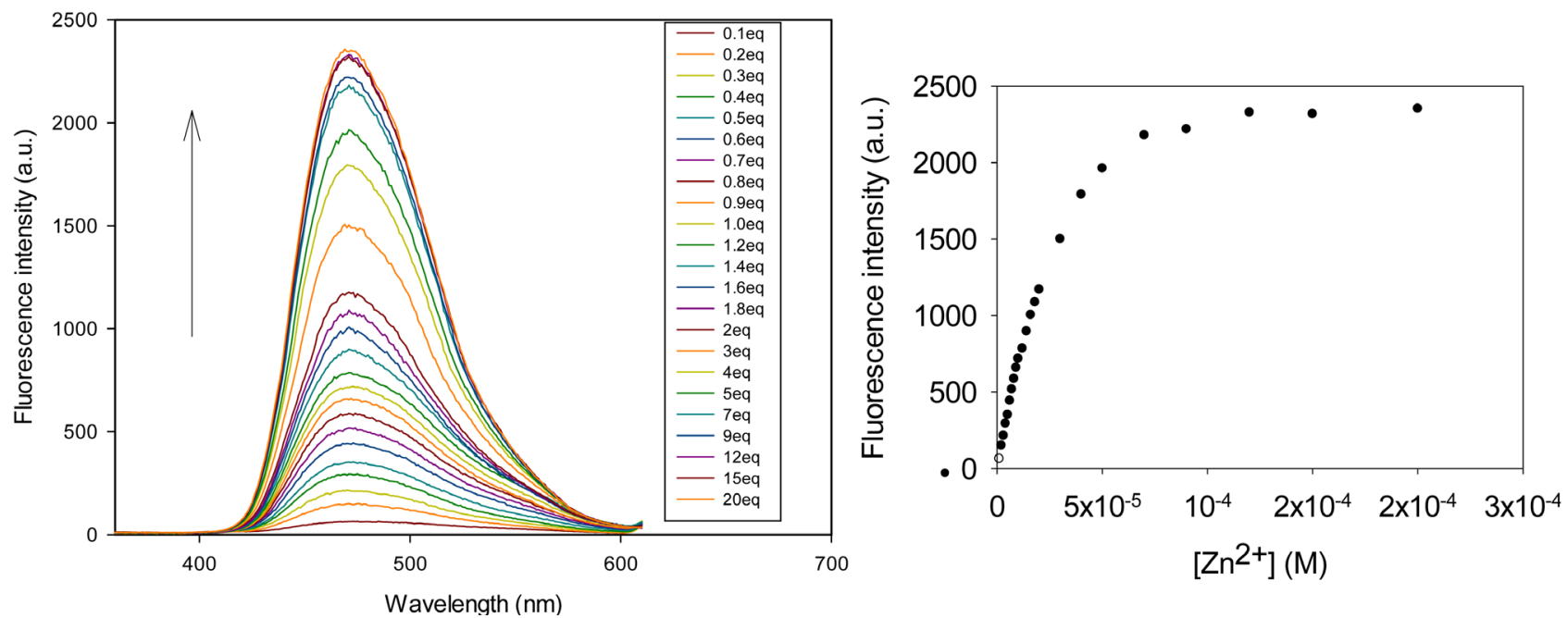

Figure 7. Fluorescence spectra of PySb $\left(10^{-5} \mathrm{M}\right)$ with increasing amount of $\mathrm{Zn}^{2+}$ in HEPES buffer solutions $\left(\mathrm{Ethanol} / \mathrm{H}_{2} \mathrm{O}=9 / 1\right.$, $\mathrm{v} / \mathrm{v}),\left(\lambda_{\mathrm{ex}}=309 \mathrm{~nm}, \lambda_{\mathrm{em}}=470 \mathrm{~nm}\right)$.

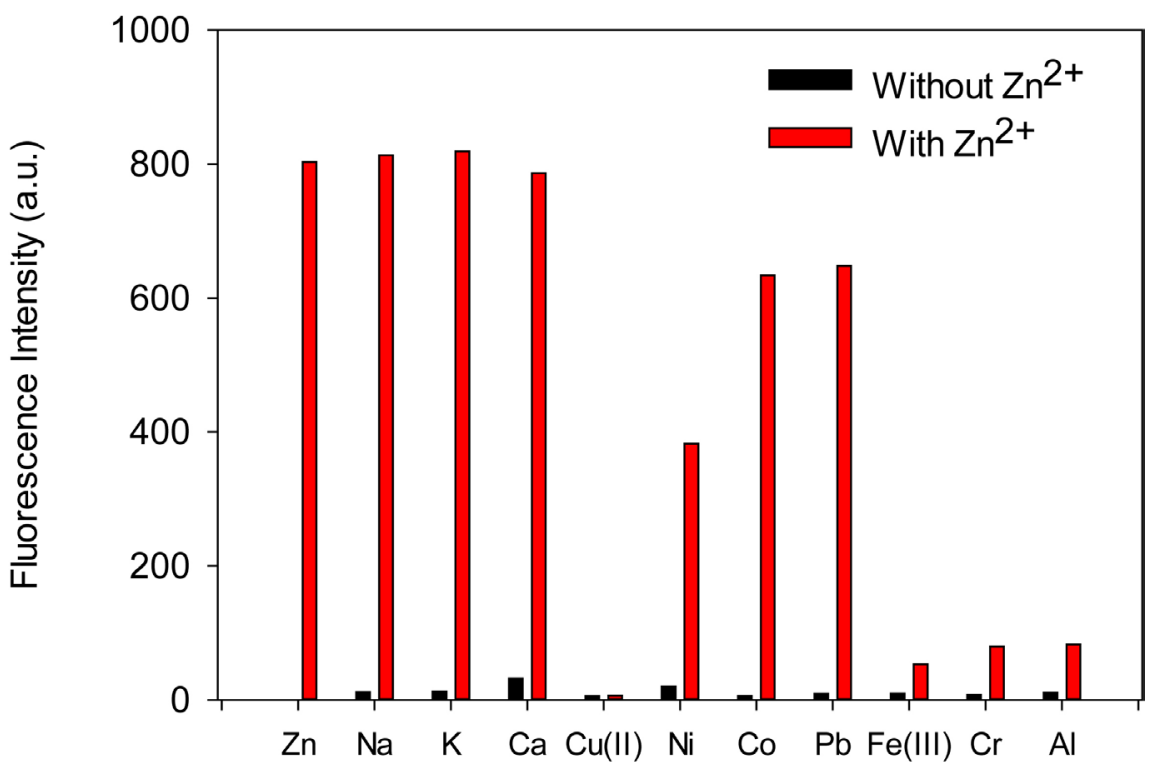

Figure 8. Fluorescence intensity of PySb $\left(10^{-5} \mathrm{M}\right)$ with various metal ions $\left(2 \times 10^{-5} \mathrm{M}\right)$ in HEPES buffer solutions (Ethanol $/ \mathrm{H}_{2} \mathrm{O}=9 / 1, \mathrm{v} / \mathrm{v}$ ), $\lambda_{\mathrm{ex}}=309 \mathrm{~nm}$. 
paramagnetic nature of $\mathrm{Cu}^{2+}$ [32] [33] [34].

In preparation of $\mathrm{PySb}$ solutions for fluorescence experiments, we observed fluorescence intensity changes of PySb in different solvents. PySb- $\mathrm{Zn}^{2+}$ exhibited stronger fluorescence intensity in ethanol than in DMF. However, ethanol was a poor solvent for PySb while DMF was a good solvent for PySb. Therefore, an experiment was carried out to investigate this interesting phenomenon. The variations of fluorescence spectra of PySb were monitored in mixture solvents of DMF and ethanol. As presented in Figure 9, the fluorescence intensity at ca. $470 \mathrm{~nm}$ first remains nearly unchanged from solutions with $100 \%$ DMF to $\mathrm{DMF} / \mathrm{ethanol}=5 / 5$. Then the intensity starts to increase gradually to DMF/ethanol $=1 / 99$. The fluorescence intensity is increased about 1.8 times in $99 \%$ ethanol solution, compared to low ethanol content solutions (0 - 50\% ethanol). Apparently, the fluorescence emission is enhanced with increasing composition of poor solvent. This phenomenon can be explained by the aggregation-induced emission enhancement (AIEE) caused by restricting intramolecular rotation (RIR). The rotation of the conjugated single bond, which links pyrene core and terminal 2-iminophenol group, consumes part of excitation energy in DMF solution. Such rotation is confined as $\mathrm{PySb}-\mathrm{Zn}^{2+}$ starts to form as nanoparticle suspensions in higher ethanol content solutions $(>50 \%)$. The formation of nanoparticle suspensions can be validated from the level-off tail in UV-Vis spectra (Figure 10) due to Mie effect [35] [36]. The result reveals that the two terminal benzene rings not only serve as a linker but also facilitate further enhancement in fluorescence intensity. Such molecular design could be applied to enhance sensitivity and detection limit of fluorescent sensors.

It is noteworthy that although ethanol is a poor solvent, ratiometric detection toward $\mathrm{Zn}^{2+}$ as discussed previously still shows good accuracy. The reason can be explained as following: The poor solubility of PySb is mainly attributed to its
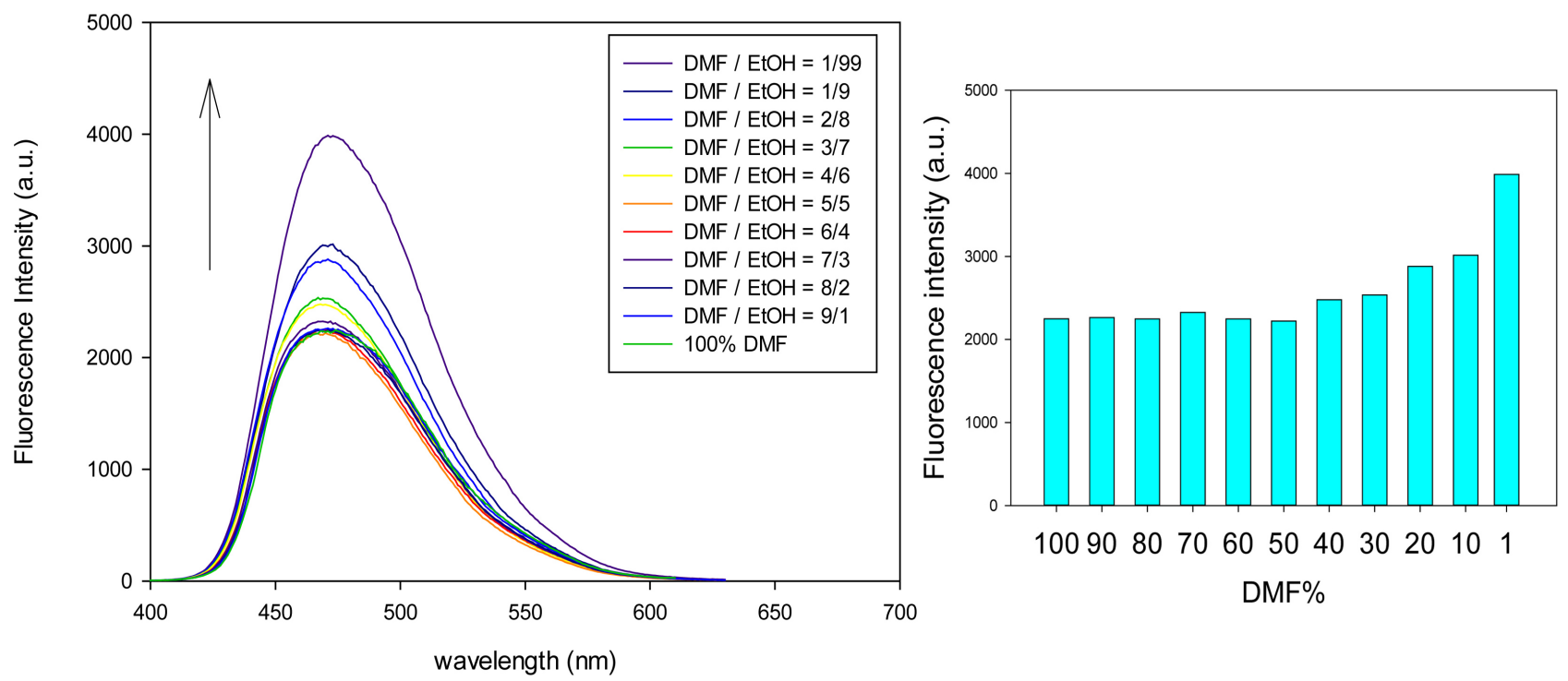

Figure 9. Fluorescence spectra of PySb $\left(10^{-5} \mathrm{M}\right)$ with $\mathrm{Zn}^{2+}\left(2 \times 10^{-4} \mathrm{M}\right)$ in different DMF/ethanol ratio solutions $\left(\lambda_{\mathrm{ex}}=324 \mathrm{~nm}\right.$, $\left.\lambda_{\text {em }}=470 \mathrm{~nm}\right)$. 


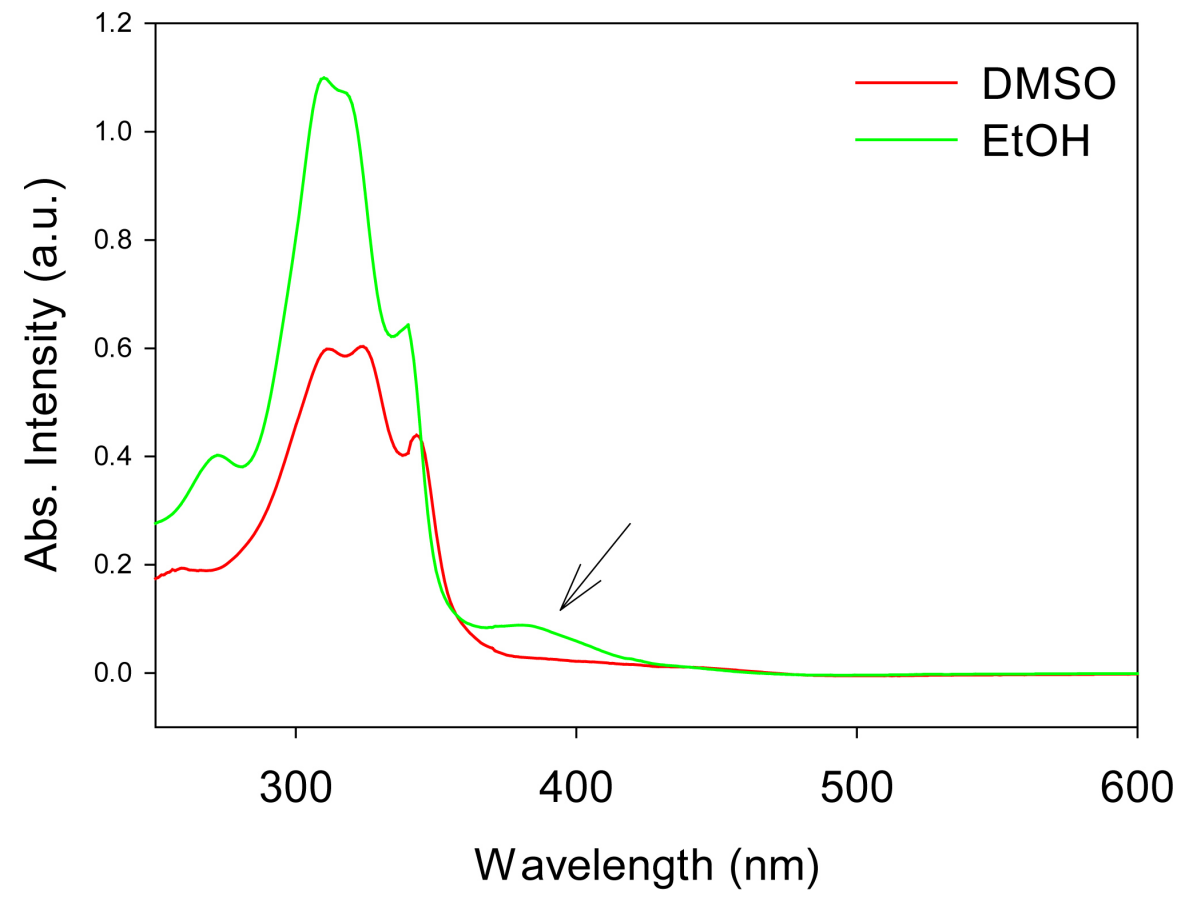

Figure 10. UV-Vis spectra of PySb $\left(10^{-5} \mathrm{M}\right)$ with $\mathrm{Zn}^{2+}$ ion $\left(2 \times 10^{-4} \mathrm{M}\right)$ in DMSO and ethanol solutions.
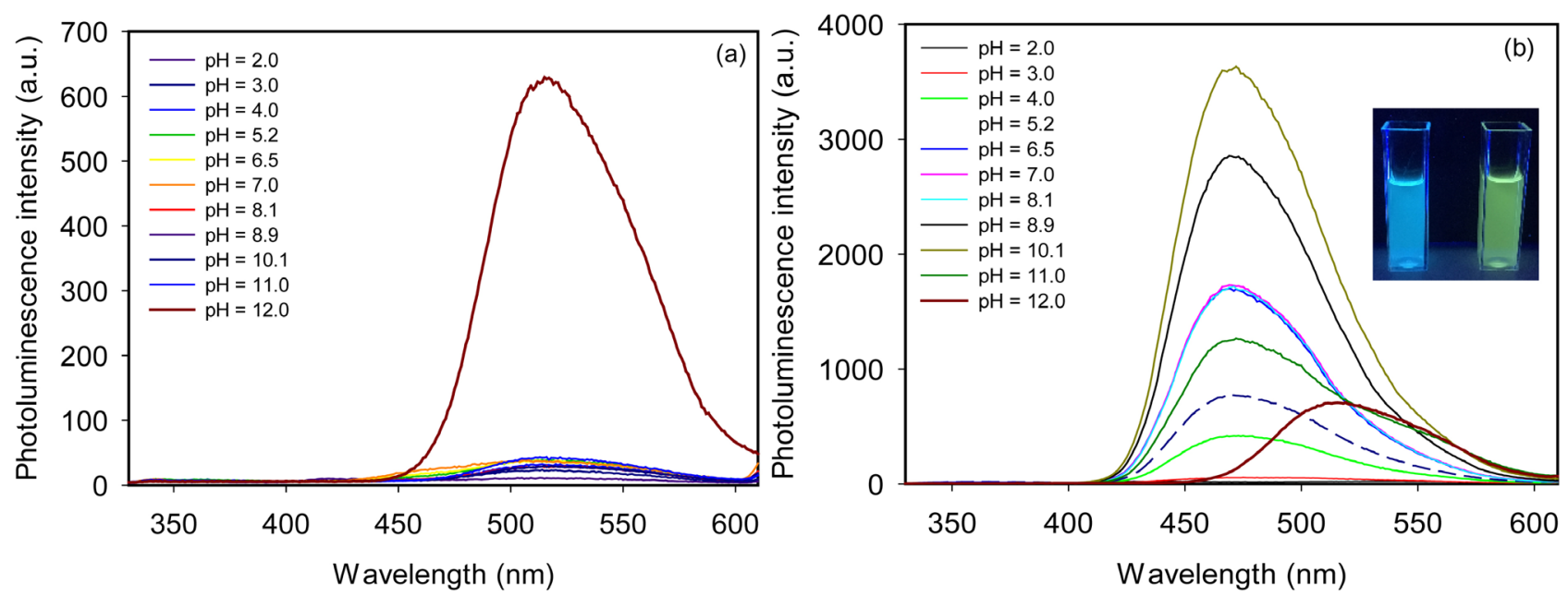

Figure 11. (a) Fluorescence spectra of $\mathrm{PySb}\left(10^{-5} \mathrm{M}\right)$ without $\mathrm{Zn}^{2+}$, (b) with $\mathrm{Zn}^{2+}$ in different $\mathrm{pH}$ solutions $\left(\mathrm{Ethanol} / \mathrm{H}_{2} \mathrm{O}=9 / 1\right.$, $\mathrm{v} / \mathrm{v}), \lambda_{\mathrm{ex}}=309 \mathrm{~nm}$.

pyrene core, whereas the binding site in 2-iminophenol group contains four polar - $\mathrm{OH}$ groups. Therefore, the binding ability toward $\mathrm{Zn}^{2+}$ is not greatly influenced in ethanol solution, and therefore data with good consistency and accuracy were obtained.

Figure 11 demonstrates $\mathrm{pH}$ responses of $\mathrm{PySb}$ with and without $\mathrm{Zn}^{2+}$ from $\mathrm{pH}$ $=2.0$ to $\mathrm{pH}=12.0$. PySb did not show significant fluorescence enhancement without $\mathrm{Zn}^{2+}$ until $\mathrm{pH}=12.0$. At $\mathrm{pH}=12.0$, an emission band at $515 \mathrm{~nm}$ appears with a fluorescence enhancement (FE) factor of 17. Clearly, the emission arises from the formation of phenolate anion in basic environment as illustrated in 
Figure 12. This significant emission enhancement can be explained by intramolecular charge transfer (ICT) [37] [38] [39]. The stronger electron-donating ability of phenolate anion strengthens its electron delocalization, resulting in an extended conjugation with benzene ring and imino moiety. The red shift of emission band from $470 \mathrm{~nm}$ to $515 \mathrm{~nm}$ indicates a chromophore change from pyrene moiety to the extended conjugated system.

In Figure 11(b), the fluorescence is still quenched in the presence of $\mathrm{Zn}^{2+}$ in

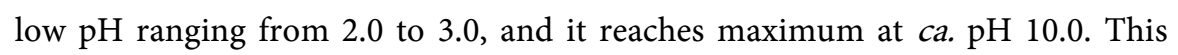
implies that the formation of $\mathrm{PySb}-\mathrm{Zn}^{2+}$ complex is more favorable at moderate high $\mathrm{pH}$ and it is inhibited by the protonation of $\mathrm{N}$ atom at low $\mathrm{pH}$. As $\mathrm{pH}$ reached 12.0, the solution exhibits the same green emission (peak at $515 \mathrm{~nm}$ ) as the one without $\mathrm{Zn}^{2+}$ (Figure 11(a)). The result reveals a competition effect between inhibited PET emission and ICT emission [40] [41] [42]. The above results validate that $\mathrm{PySb}$ can serve as a $\mathrm{Zn}^{2+}$ sensor in a wide $\mathrm{pH}$ range. Besides, $\mathrm{H}^{+}$and $\mathrm{OH}^{-}$do not generate confusing signals against $\mathrm{Zn}^{2+}$ sensing, which is rare for Schiff base PET sensors [43].

\subsection{Photophysical Properties in Buffered DMSO Solution}

Next, we investigated the photophysical properties of PySb in DMSO solution. The absorption spectra [Figure 13(a)] shows similar result to those in ethanol buffer solutions, both metal ions have interactions with PySb. Interestingly, PySb exhibits different fluorescence responses in DMSO solutions [Figure 13(b)]. The fluorescence with addition of $\mathrm{Zn}^{2+}$ became indistinct, while addition of $\mathrm{Al}^{3+}$

(a)<smiles>OCC(/C=N/c1cc(-c2ccc(O)c(/C=N/C(CO)(CO)CO)c2)ccc1/C=N/C(CO)(CO)CO)(CO)CO</smiles>

(b)

PET

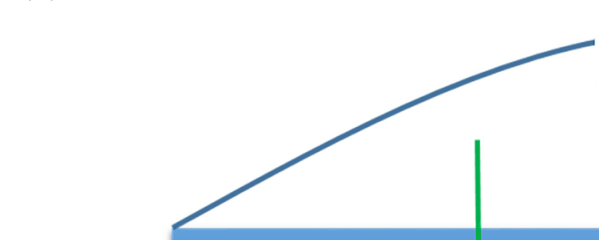

dominate

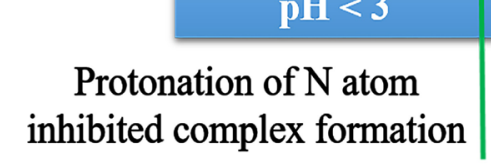

$\mathrm{pH}=3 \sim 11$

$\mathrm{PySb}-\mathrm{Zn}^{2+}$ Complex

formation favorable

ICT

dominate

$\mathrm{pH}>12>\mathrm{pH}$

Phenolate

formation

Figure 12. (a) Formation of phenolate anion at high pH; (b) Competition between PET and ICT mechanisms. 

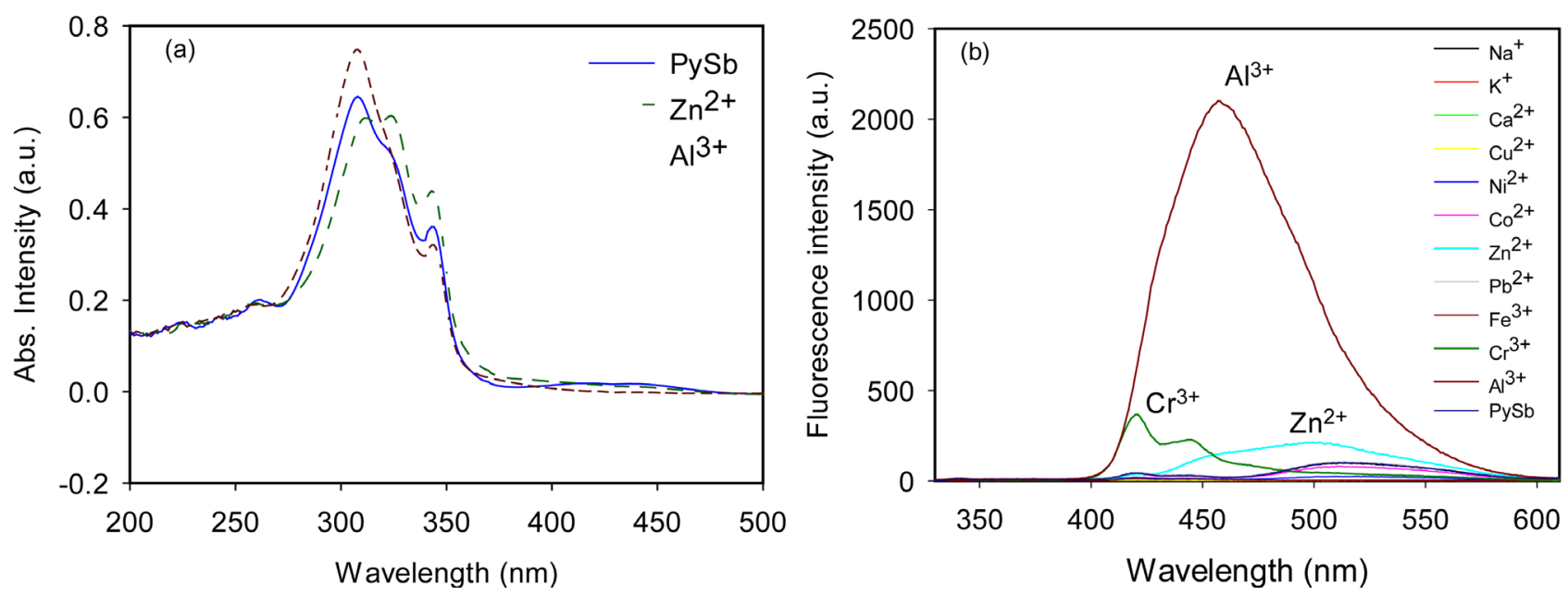

Figure 13. (a) UV-Vis spectra of PySb $\left(10^{-5} \mathrm{M}\right)$ with $\mathrm{Zn}^{2+}$ and $\mathrm{Al}^{3+}$ metal ions $\left(2 \times 10^{-4} \mathrm{M}\right)$; (b) Fluorescence spectra of PySb $\left(10^{-5}\right.$ $\mathrm{M})$ with various metal ions $\left(2 \times 10^{-4} \mathrm{M}\right)$ in HEPES buffer solution $\left(\mathrm{DMSO} / \mathrm{H}_{2} \mathrm{O}=9 / 1, \mathrm{v} / \mathrm{v}\right)$.
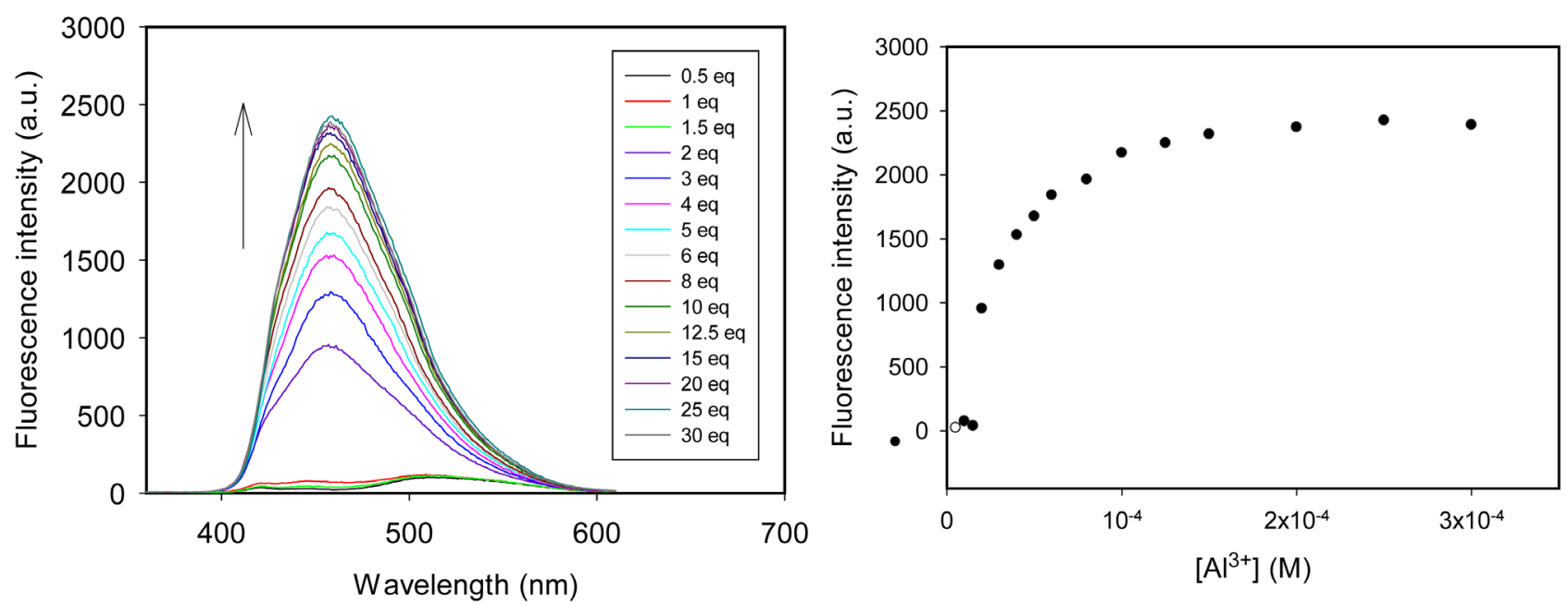

Figure 14. Fluorescence spectra of PySb $\left(10^{-5} \mathrm{M}\right)$ with increasing amount of $\mathrm{Al}^{3+}$ in $\mathrm{HEPES}$ buffer solutions $\left(\mathrm{DMSO} / \mathrm{H}_{2} \mathrm{O}=9 / 1\right.$, $\mathrm{v} / \mathrm{v}),\left(\lambda_{\mathrm{ex}}=309 \mathrm{~nm}, \lambda_{\mathrm{em}}=458 \mathrm{~nm}\right)$.

generated strong fluorescence enhancement. $\mathrm{Cr}^{3+}$ also induced weak fluorescence enhancement but with a deeper blue color. Therefore, it appears that PySb can serve as $\mathrm{Al}^{3+}$ sensor in DMSO solution.

The sensitivity of PySb toward $\mathrm{Al}^{3+}$ in DMSO solution was investigated by titration experiment as depicted in Figure 14. Surprisingly, PySb did not exhibit fluorescence enhancement until two equivalents of $\mathrm{Al}^{3+}$ were added. This result reveals that when PySb is dissolved in DMSO solution, strong fluorescence is generated only when both binding sites are chelated with $\mathrm{Al}^{3+}$. It is reasonable to suppose that the quenching ability of imine moieties varies with solvents. In DMSO, both imine moieties can quench the fluorescence completely through the PET mechanism, thus the fluorescence is recovered only when both binding sites are chelated with $\mathrm{Al}^{3+}$. On the contrary, in ethanol the quenching ability of imine moieties is less than $100 \%$, so the fluorescence can be recovered when one of the binding sites is chelated with $\mathrm{Zn}^{2+}$. Since PySb did not show fluorescence 
response until two equivalent of $\mathrm{Al}^{3+}$ were added, the investigation of Job plot, binding constant and detection limit could not be conducted.

Figure 15 demonstrates competition effects from other metal ions against $\mathrm{Al}^{3+}$ sensing. Aside from $\mathrm{Cu}^{2+}$ which completely quenched the fluorescence as in ethanol solutions, only $\mathrm{Fe}^{3+}$ partially decreased fluorescence intensity. The result agrees with the observation in ethanol solutions that PySb exhibits higher binding tendency toward $\mathrm{Al}^{3+}$. Thus PySb can serve as a highly selective $\mathrm{Al}^{3+}$ sensor in DMSO solution.

\section{4. ${ }^{1} \mathrm{H}$ NMR Spectra of PySb-Znn ${ }^{2+}$ and PySb-Al ${ }^{3+}$ Complexes}

The formation of PySb- $\mathrm{Zn}^{2+}$ complex was further investigated by ${ }^{1} \mathrm{H}$ NMR spectra in deuterated N,N-dimethylformamide (DMF- $\mathrm{d}_{7}$, Figure 16). The one at the bottom represents ${ }^{1} \mathrm{H}$ NMR spectrum of free PySb in DMF- $\mathrm{d}_{7}$, three solvent peaks of DMF, one solvent peak of $\mathrm{H}_{2} \mathrm{O}$ and all proton signals, except for the proton $\mathrm{f}$ which merged into DMF solvent peak near $8.0 \mathrm{ppm}$, of PySb have been assigned. Upon addition of $\mathrm{Zn}^{2+}$ the signal of phenolic proton (a) significantly shifted from $14.66 \mathrm{ppm}$ to $11.25 \mathrm{ppm}$, whereas the signal of alcoholic protons $(\mathrm{h})$ at about $4.93 \mathrm{ppm}$ split into three broad peaks ranging from 5 - $7 \mathrm{ppm}$. However, no shift was observed for the peak of imine protons (b) at $8.92 \mathrm{ppm}$, but the peak became much broader. The above phenomena indicate that the three alcoholic $-\mathrm{OH}$, phenolic $-\mathrm{OH}$ and $-\mathrm{H}$ on $\mathrm{C}=\mathrm{N}$ bond have interactions with $\mathrm{Zn}^{2+}$. Moreover, a new signal appeared at $10.43 \mathrm{ppm}$, suggesting that the formation of

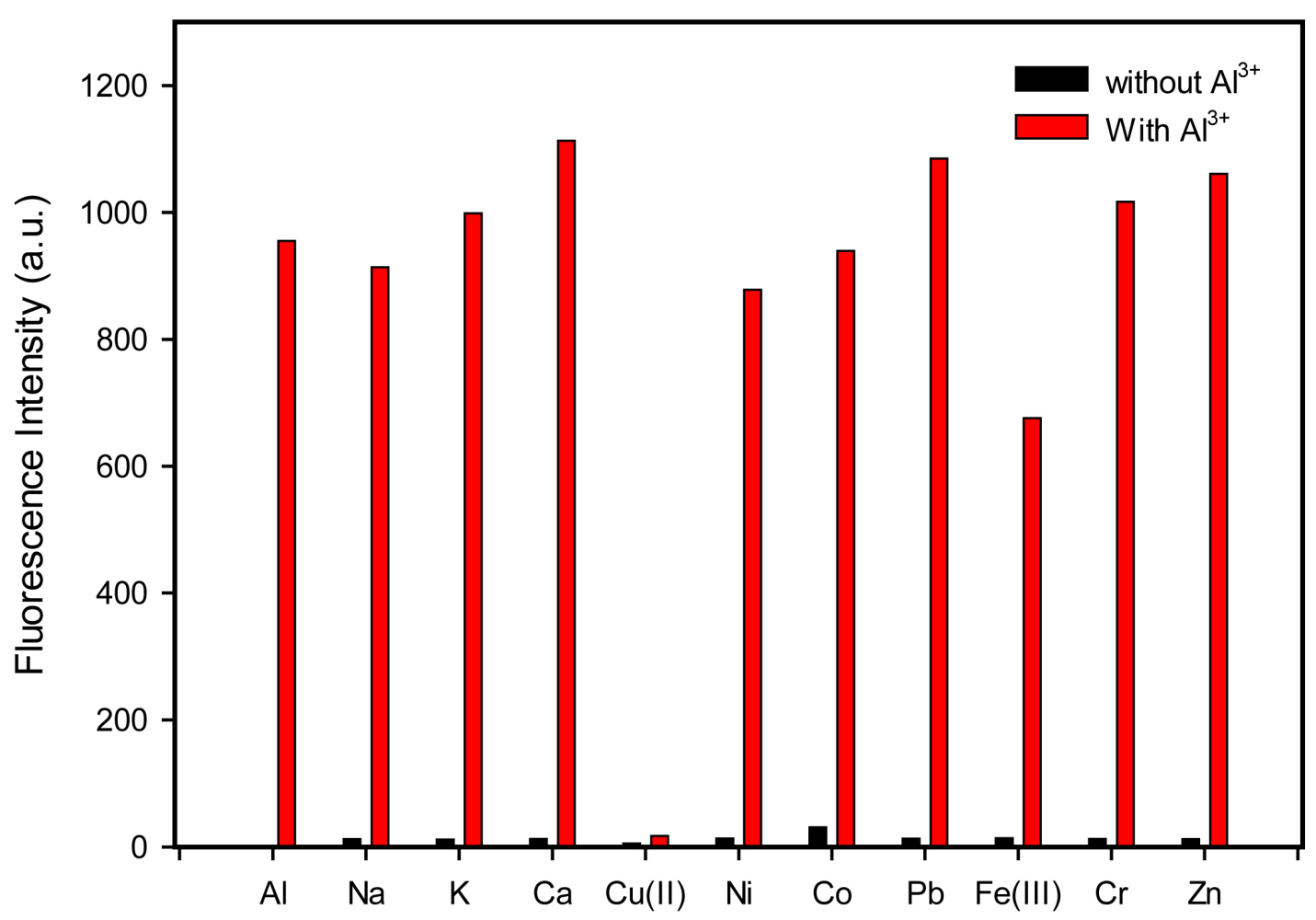

Figure 15. Fluorescence spectra of PySb $\left(10^{-5} \mathrm{M}\right)$ with various metal ions $\left(2 \times 10^{-5} \mathrm{M}\right)$ in HEPES buffer solutions $\left(\mathrm{DMSO} / \mathrm{H}_{2} \mathrm{O}=9 / 1, \mathrm{v} / \mathrm{v}\right), \lambda_{\mathrm{ex}}=309 \mathrm{~nm}$. 

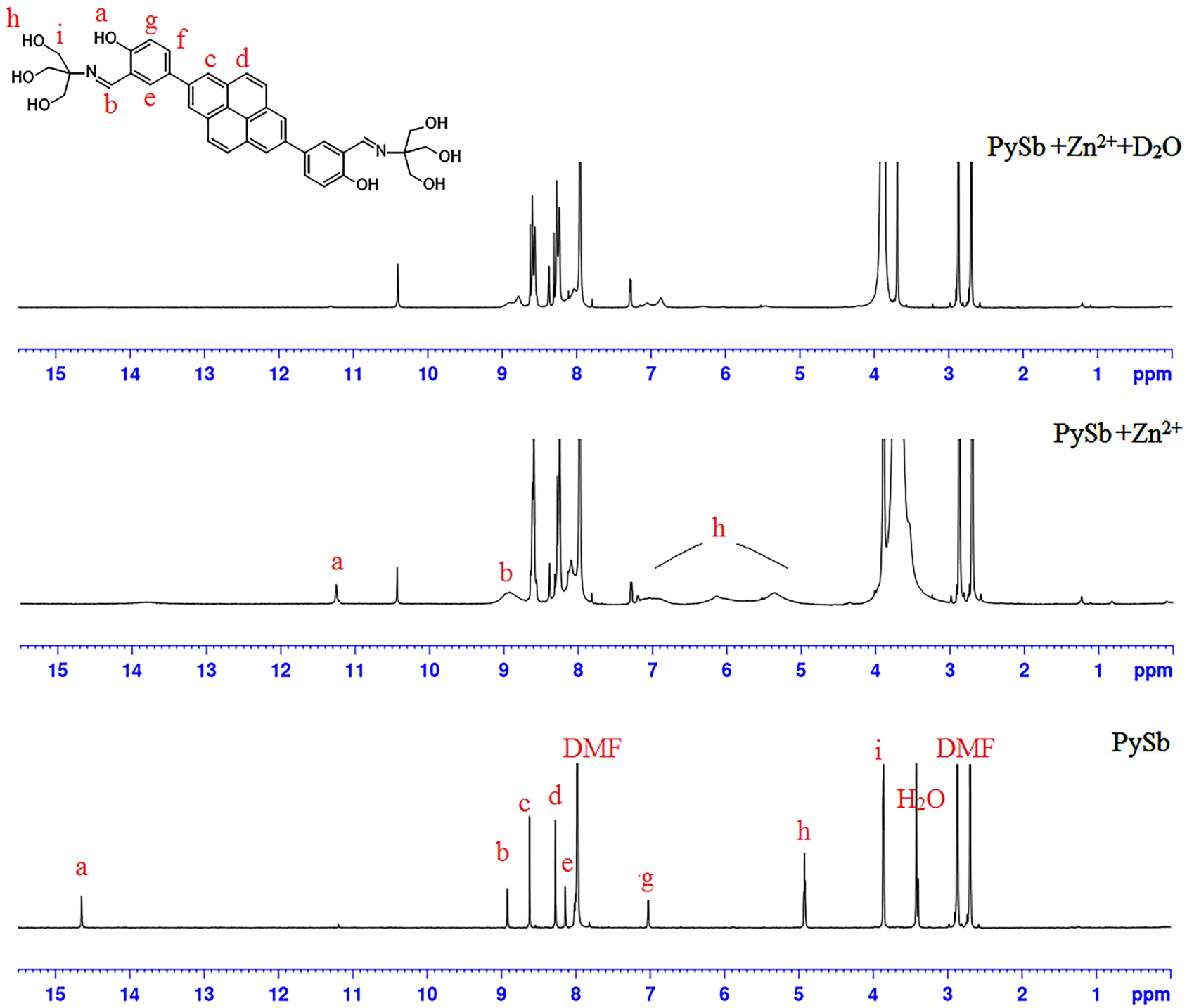

Figure 16. ${ }^{1} \mathrm{H}$ NMR of free PySb (bottom), $\mathrm{PySb}+\mathrm{Zn}^{2+}$ (middle), and $\mathrm{PySb}+\mathrm{Zn}^{2+}+\mathrm{D}_{2} \mathrm{O}$ (upper).

PySb- $\mathrm{Zn}^{2+}$ complex might involve an additional hydroxide ion $\left(\mathrm{OH}^{-}\right)$. The disappearance of signals of alcoholic (h) and alcoholic protons (a) after addition of $\mathrm{D}_{2} \mathrm{O}$ confirms the presence of these exchangeable protons.

${ }^{1} \mathrm{H}$ NMR spectra of PySb- $\mathrm{Al}^{3+}$ complex in DMSO (Figure 17) shows similar results, but the changes in proton signals are much smaller than in DMF. In fact, it took a long time for PySb to reach saturated fluorescence intensity with $\mathrm{Al}^{3+}$ (about $3 \mathrm{hr}$ ). Therefore, the small signal changes are probably due to slow formation of PySb- $\mathrm{Al}^{3+}$ complex.

\section{Conclusion}

An efficient fluorescent sensor PySb comprising of pyrene moiety as the fluorophore, benzene ring as the spacer, and 2-(hydroxymethyl)propane-1,3-diol as the ionophore was successfully synthesized and characterized. The PySb itself exhibited weak fluorescence due to PET mechanism; however, the fluorescence 


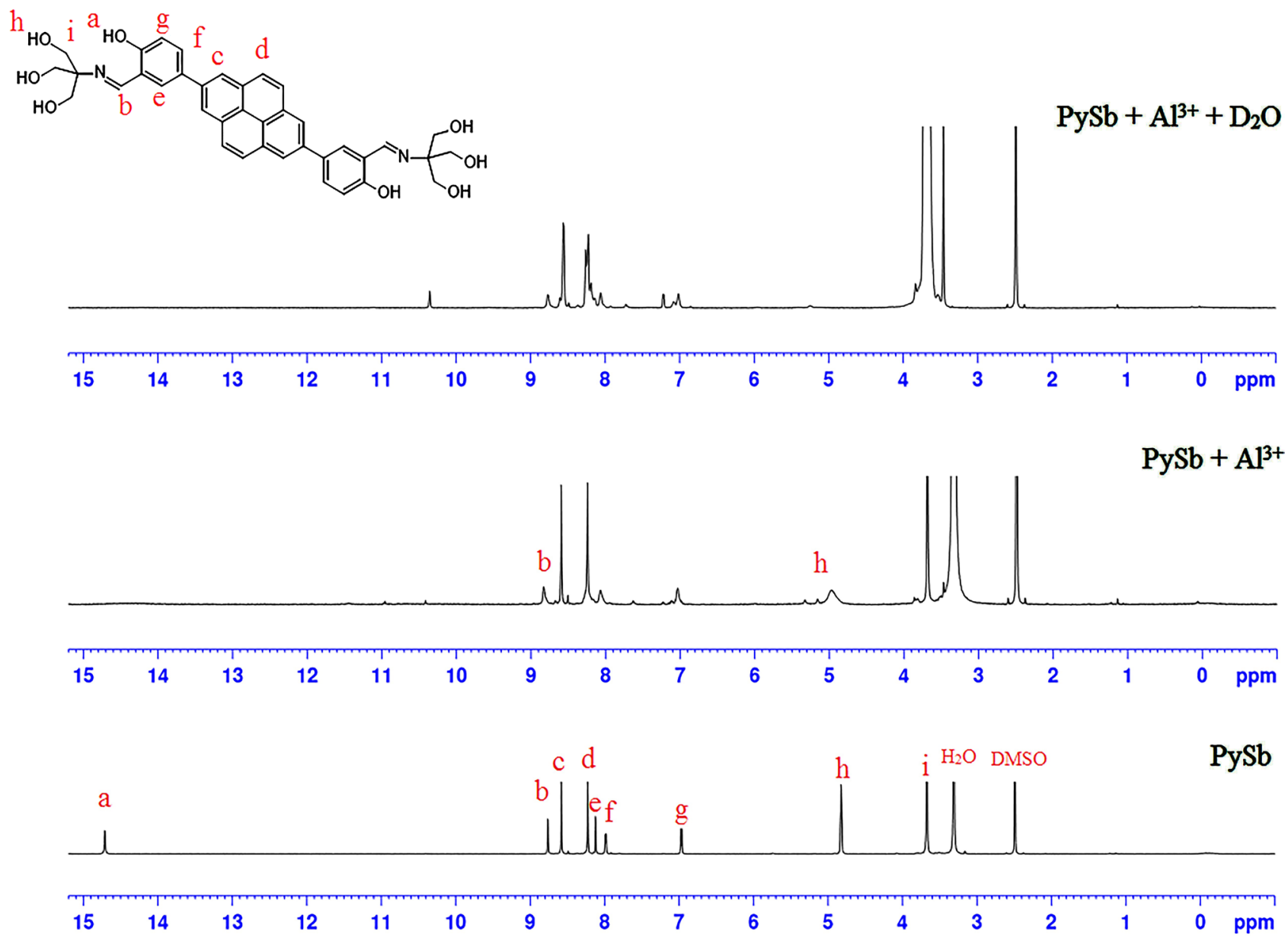

Figure 17. ${ }^{1} \mathrm{H}$ NMR spectra of free PySb (bottom), $\mathrm{PySb}+\mathrm{Al}^{3+}$ (middle), and $\mathrm{PySb}+\mathrm{Al}^{3+}+\mathrm{D}_{2} \mathrm{O}$ (upper).

was turned on by $\mathrm{Zn}^{2+}$ in ethanol solution $\left(\lambda_{\mathrm{em}}=470 \mathrm{~nm}\right)$ and by $\mathrm{Al}^{3+}$ in DMSO solution $\left(\lambda_{\mathrm{em}}=458 \mathrm{~nm}\right)$. The complexes of PySb-Zn ${ }^{2+}$ and PySb-Al ${ }^{3+}$ were further confirmed by ${ }^{1} \mathrm{H}$ NMR spectra. The stoichiometric ratio between PySb and $\mathrm{Zn}^{2+}$ was 1:2, as obtained from the Job plot. Based on the titration experiment, limit of detection (LOD) and binding constant toward $\mathrm{Zn}^{2+}$ were $2.39 \times 10^{-8} \mathrm{M}$ and $2 \times 10^{9} \mathrm{M}^{-1}$, respectively. The PySb- $\mathrm{Zn}^{2+}$ complex in DMF solution showed aggregation-induced emission enhancement with increasing content of ethanol. It can be utilized as a fluorescent sensor in a wide range of $\mathrm{pH}(3-11)$. Green emission of PySb $\left(\lambda_{\mathrm{em}}=515 \mathrm{~nm}\right)$ was observed when $\mathrm{pH}$ was higher than 12 due to ICT mechanism. Current results indicate that PySb is a promising fluorescent "turn on" sensor for $\mathrm{Zn}^{2+}$ and $\mathrm{Al}^{3+}$ in ethanol and DMSO, respectively.

\section{Acknowledgements}

Authors are thankful to Ministry of Science and Technology, Taiwan for financial support through grant MOST 105-2221-E-006-250. This research was partially funded by the Headquarters of University Advancement at National Cheng Kung University, under the sponsorship of the Ministry of Education, Taiwan. 


\section{References}

[1] Outten, C.E., Tobin, D.A., Penner-Hahn, J.E. and O’Halloran, T.V. (2001) Characterization of the Metal Receptor Sites in Escherichia coli Zur, an Ultrasensitive Zinc(II) Metalloregulatory Protein. Biochemistry, 40, 10417-10423. https://doi.org/10.1021/bi0155448

[2] Finney, L.A. and O’Halloran, T.V. (2003) Transition Metal Speciation in the Cell: Insights from the Chemistry of Metal Ion Receptors. Science, 300, 931-936. https://doi.org/10.1126/science.1085049

[3] Frederickson, C.J. (1989) Neurobiology of Zinc and Zinc-Containing Neurons. In: John, R.S. and Ronald, J.B., Eds., International Review of Neurobiology, Academic Press, Cambridge, 145-238. https://doi.org/10.1016/S0074-7742(08)60279-2

[4] Zalewski, P.D., Millard, S.H., Forbes, I.J., Kapaniris, O., Slavotinek, A., Betts, W.H., Ward, A.D., Lincoln, S.F. and Mahadevan, I. (1994) Video Image Analysis of Labile Zinc in Viable Pancreatic Islet Cells Using a Specific Fluorescent Probe for Zinc. Journal of Histochemistry and Cytochemistry, 42, 877-884. https://doi.org/10.1177/42.7.8014471

[5] Kikuchi, K., Komatsu, K. and Nagano, T. (2004) Zinc Sensing for Cellular Application. Current Opinion in Chemical Biology, 8, 182-191. https://doi.org/10.1016/j.cbpa.2004.02.007

[6] Bush, A.I. (2003) The Metallobiology of Alzheimer's Disease. Trends in Neuroscience, 26, 207-214.

[7] Truong-Tran, A.Q., Carter, J., Ruffin, R.E. and Zalewski, P.D. (2001) The Role of Zinc in Caspase Activation and Apoptotic Cell Death. Biometals, 14, 315-330. https://doi.org/10.1023/A:1012993017026

[8] Álvarez, E., Fernández-Marcos, M.L., Monterroso, C. and Fernández-Sanjurjo, M.J. (2005) Application of Aluminum Toxicity Indices to Soils under Various Forest Species. Forest Ecology Management, 211, 227-239. https://doi.org/10.1016/j.foreco.2005.02.044

[9] Panda, S.K., Baluska, F. and Matsumoto, H. (2009) Aluminum Stress Signaling in Plants. Plant Signaling \& Behavior, 4, 592-597. https://doi.org/10.4161/psb.4.7.8903

[10] Walton, J.R. (2007) An Aluminum-Based Rat Model for Alzheimer's Disease Exhibits Oxidative Damage, Inhibition of PP2A Activity, Hyperphosphorylated Tau, and Granulovacuolar Degeneration. Journal of Inorganic Biochemistry, 101, 1275-1284. https://doi.org/10.1016/j.jinorgbio.2007.06.001

[11] Fasman, G.D. (1996) Aluminum and Alzheimer's Disease: Model Studies. Coordination Chemical Reviews, 149, 125-165.

[12] Perl, D., Gajdusek, D., Garruto, R., Yanagihara, R. and Gibbs, C. (1982) Intraneuronal Aluminum Accumulation in Amyotrophic Lateral Sclerosis and Parkinsonism-Dementia of Guam. Science, 217, 1053-1055. https://doi.org/10.1126/science.7112111

[13] Kursunlu, A.N. (2015) A Fluorescent "Turn on" Chemosensor Based on Bodipy-Anthraquinone for Al (III) Ions: Synthesis and Complexation/Spectroscopic Studies. RSC Advances, 5, 41025-41032. https://doi.org/10.1039/C5RA03342J

[14] Kursunlu, A.N., Gunler, E., Ucan, H.I. and Boyle, R.W. (2012) A Novel Bod-ipyDipyrrin Fluorescent Probe: Synthesis and Recognition Behaviour towards Fe (II) and Zn (II). Dyes and Pigments, 94, 496-502. https://doi.org/10.1016/j.dyepig.2012.02.006

[15] Nuri Kursunlu, A.N., Şahin, E. and Güler, E. (2016) Cu (II) Chemosensor Based on 
a Fluorogenic Bodipy-Salophen Combination: Sensitivity and Selectivity Studies. Journal of fluorescence, 26, 1997-2004. https://doi.org/10.1007/s10895-016-1893-1

[16] Hobday, M.D. and Smith, T.D. (1973) N,N’-Ethylenebis(salicylideneiminato) Transition Metal Ion Chelates. Coordination Chemical Reviews, 9, 311-337. https://doi.org/10.1016/S0010-8545(00)82081-0

[17] Riley, D.P., Busch, D.H., Fenton, D.E. and Lintvedt, R.L. (2007) Macrocyclic Tetraazatetraenato Ligands and Their Metal Complexes, in Inorganic Syntheses. John Wiley \& Sons, Inc., Hoboken, 36-44.

[18] Cozzi, P.G. (2004) Metal-Salen Schiff Base Complexes in Catalysis: Practical Aspects. Chemical Society Reviews, 33, 410-421. https://doi.org/10.1039/B307853C

[19] Zhou, Y., Li, Z.-X., Zang, S.-Q., Zhu, Y.-Y., Zhang, H.-Y., Hou, H.-W. and Mak, T.C.W. (2012) A Novel Sensitive Turn-on Fluorescent $\mathrm{Zn}^{2+}$ Chemosensor Based on an Easy to Prepare C3-Symmetric Schiff-Base Derivative in 100\% Aqueous Solution. Organic Letters, 14, 1214-1217. https://doi.org/10.1021/ol2034417

[20] Hsieh, W.H., Wan, C.-F., Liao, D.-J. and Wu, A.-T. (2012) A Turn-On Schiff Base Fluorescence Sensor for Zinc Ion. Tetrahedron Letters, 53, 5848-5851. https://doi.org/10.1016/j.tetlet.2012.08.058

[21] Yan, M.H., Li, T.-R. and Yang, Z.-Y. (2011) A Novel Coumarin Schiff-Base as a $\mathrm{Zn}(\mathrm{II})$ Ion Fluorescent Sensor. Inorganic Chemistry Communications, 14, 463-465. https://doi.org/10.1016/j.inoche.2010.12.027

[22] Lee, S.A., You, G.R., Choi, Y.W., Jo, H.Y., Kim, A.R., Noh, I., Kim, S.J., Kim, Y. and Kim, C. (2014) A New Multifunctional Schiff Base as a Fluorescence Sensor for $\mathrm{Al}^{3+}$ and a Colorimetric Sensor for $\mathrm{CN}^{-}$in Aqueous Media: an Application to Bioimaging. Dalton Transactions, 43, 6650-6659. https://doi.org/10.1039/C4DT00361F

[23] Gupta, V.K., Singh, A.K. and Kumawat, L.K. (2014) Thiazole Schiff Base Turn-On Fluorescent Chemosensor for $\mathrm{Al}^{3+}$ Ion. Sensors and Actuators B: Chemical, 195, 98-108. https://doi.org/10.1016/j.snb.2013.12.092

[24] Chen, C.H., Liao, D.J., Wan, C.F. and Wu, A.T. (2013) A Turn-On and Reversible Schiff Base Fluorescence Sensor for $\mathrm{Al}^{3+}$ Ion. Analyst, 138, 2527-2530. https://doi.org/10.1039/c3an00004d

[25] Anand, T., Sivaraman, G., Mahesh, A. and Chellappa, D. (2015) Aminoquinoline Based Highly Sensitive Fluorescent Sensor for Lead(II) and Aluminum(III) and Its Application in Live Cell Imaging. Analytica Chimica Acta, 853, 596-601. https://doi.org/10.1016/j.aca.2014.11.011

[26] Komatsu, K., Kikuchi, K., Kojima, H., Urano, Y. and Nagano, T. (2005) Selective Zinc Sensor Molecules with Various Affinities for $\mathrm{Zn}^{2+}$, Revealing Dynamics and Regional Distribution of Synaptically Released $\mathrm{Zn}^{2+}$ in Hippocampal Slices. Journal of American Chemical Society, 127, 10197-10204. https://doi.org/10.1021/ja050301e

[27] Liu, Z., Li, Y., Ding, Y., Yang, Z., Wang, B., Li, Y., Li, T., Luo, W., Zhu, W., Xie, J. and Wang, C. (2014) Water-Soluble and Highly Selective Fluorescent Sensor from Naphthol Aldehyde-Tris Derivate for Aluminium Ion Detection. Sensors and Actuattors B: Chemical, 197, 200-205.

[28] Sinha, S., Mukherjee, T., Mathew, J., Mukhopadhyay, S.K. and Ghosh, S. (2014) Green-Emissive Molecular Marker with a TRIS-Scaffold for Fluorescence Imaging of $\mathrm{Zn}^{2+}$ in Biological Systems. Journal of Photochemistry and Photobiology A: Chemistry, 277, 75-81. https://doi.org/10.1016/j.jphotochem.2013.12.012

[29] Qiao, Y., Zhang, J., Xu, W. and Zhu, D. (2011) Novel 2,7-substituted Pyrene Derivatives: Syntheses, Solid-State Structures, and Properties. Tetrahedron, 67, 3395-3405. https://doi.org/10.1016/j.tet.2011.03.055 
[30] Ding, W.H., Cao, W., Zheng, X.J., Ding, W.J., Qiao, J.P. and Jin, L.P. (2014) A Tetrazole-Based Fluorescence "Turn-On" Sensor for $\mathrm{Al}(\mathrm{III})$ and $\mathrm{Zn}$ (II) Ions and Its Application in Bioimaging. Dalton Transactions, 43, 6429-6435. https://doi.org/10.1039/C4DT00009A

[31] Choi, Y.W., Park, G.J., Na, Y.J., Jo, H.Y., Lee, S.A., You, G.R. and Kim, C. (2014) A Single Schiff Base Molecule for Recognizing Multiple Metal Ions: A Fluorescence Sensor for $\mathrm{Zn}(\mathrm{II})$ and $\mathrm{Al}(\mathrm{III})$ and Colorimetric Sensor for Fe(II) and Fe(III). Sensors and Actuators B: Chemical, 194, 343-352. https://doi.org/10.1016/j.snb.2013.12.114

[32] Hung, C.-H., Chang, G.-F., Kumar, A., Lin, G.-F., Luo, L.-Y., Ching, W.-M. and Diau, E.W.-G. (2008) m-Benziporphodimethene: A New Porphyrin Analogue Fluorescence Zinc(ii) Sensor. Chemical Communications, 8, 978-980. https://doi.org/10.1039/B714412A

[33] Chen, H., Gao, W., Zhu, M., Gao, H., Xue, J. and Li, Y. (2010) A Highly Selective OFF-ON Fluorescent Sensor for Zinc in Aqueous Solution and Living Cells. Chemical Communications, 46, 8389-8391. https://doi.org/10.1039/c0cc02134b

[34] Zhang, T.-T., Chen, X.-P., Liu, J.-T., Zhang, L.-Z., Chu, J.-M., Su, L. and Zhao, B.-X. (2014) A High Sensitive Fluorescence Turn-On Probe for Imaging $\mathrm{Zn}^{2+}$ in Aqueous Solution and Living Cells. RSC Advances, 4, 16973-16978.

https://doi.org/10.1039/c4ra00584h

[35] Tang, B.Z., Geng, Y., Lam, J.W.Y., Li, B., Jing, X., Wang, X., Wang, A.B., Pakhomov, F. and Zhang, X.X. (1999) Processible Nanostructured Materials with Electrical Conductivity and Magnetic Susceptibility: Preparation and Properties of Maghemite/Polyaniline Nanocomposite Films. Chemistry of Materials, 11, 1581-1589. https://doi.org/10.1021/cm9900305

[36] Tong, H., Hong, Y., Dong, Y., Haussler, M., Lam, J.W., Li, Z., Guo, Z., Guo, Z. and Tang, B.Z. (2006) Fluorescent "Light-Up" Bioprobes Based on Tetraphenylethylene Derivatives with Aggregation-Induced Emission Characteristics. Chemical Communications, 35, 3705-3707. https://doi.org/10.1039/B608425G

[37] Song, P., Chen, X., Xiang, Y., Huang, L., Zhou, Z., Wei, R. and Tong, A. (2011) A Ratiometric Fluorescent pH Probe Based on Aggregation-Induced Emission Enhancement and Its Application in Live-Cell Imaging. Journal of Materials Chemistry, 21, 13470-13475. https://doi.org/10.1039/c1jm12098k

[38] Saha, U.C., Dhara, Chattopadhyay, K.B., Mandal, S.K., Mondal, S., Sen, S., Mukherjee, M., van Smaalen, S. and Chattopadhyay, P. (2011) A New Half-Condensed Schiff Base Compound: Highly Selective and Sensitive pH-Responsive Fluorescent Sensor. Organic Letters, 13, 4510-4513. https://doi.org/10.1021/ol201652r

[39] Fan, Y., Zhu, Y.M., Dai, F.R., Zhang, L.Y. and Chen, Z.N. (2007) Photophysical and Anion Sensing Properties of Platinum(II) Terpyridyl Complexes with Phenolic Ethynyl Ligands. Dalton Transactions, 35, 3885-3892. https://doi.org/10.1039/b707797a

[40] Joshi, H., Kamounah, F.S., Gooijer, C., van der Zwan, G. and Antonov, L. (2002) Excited State Intramolecular Proton Transfer in Some Tautomeric Azo Dyes and Schiff Bases Containing an Intramolecular Hydrogen Bond. Journal of Photochemistry and Photobiology A: Chemistry, 152, 183-191. https://doi.org/10.1016/S1010-6030(02)00155-7

[41] Gormin, D. and Kasha, M. (1988) Triple Fluorescence in Aminosalicylates. Modulation of Normal, Proton-Transfer, and Twisted Intramolecular Charge-Transfer (TICT) Fluorescence by Physical and Chemical Perturbations. Chemical Physics Letters, 153, 574-576. https://doi.org/10.1016/0009-2614(88)85263-1 
[42] Guo, Z., Zhao, P., Zhu, W., Huang, X., Xie, Y. and Tian, H. (2008) Intramolecular Charge-Transfer Process Based on Dicyanomethylene-4H-pyran Derivative: An Integrated Operation of Half-Subtractor and Comparator. Journal of Physical Chemistry $C, 112,7047-7053$. https://doi.org/10.1021/jp0777162

[43] de Silva, A.P., Gunnlaugsson, T. and Rice, T.E. (1996) Recent Evolution of Luminescent Photoinduced Electron Transfer Sensors. A Review. Analyst, 121, 1759-1762. https://doi.org/10.1039/an9962101759

[44] Varghese, R., George, S.J. and Ajayaghosh, A. (2005) Anion Induced Modulation of Self-Assembly and Optical Properties in Urea End-Capped Oligo(p-phenylenevinylene)s. Chemical Communications, No. 5, 593-595.

https://doi.org/10.1039/b413909g

[45] Dalapati, S., Alam, M.A., Jana, S. and Guchhait, N. (2011) Naked-Eye Detection of $\mathrm{F}^{-}$and $\mathrm{AcO}^{-}$Ions by Schiff Base Receptor. Journal of Fluorine Chemistry, 132, 536-540. https://doi.org/10.1016/j.jfluchem.2011.05.025

[46] Erdemir, S., Kocyigit, O. and Malkondu, S. (2015) Fluorogenic Recognition of $\mathrm{Zn}^{2+}$, $\mathrm{Al}^{3+}$ and $\mathrm{F}^{-}$Ions by a New Multi-Analyte Chemosensor Based Bisphenol A-Quinoline. Journal of Fluorescence, 25, 719-727. https://doi.org/10.1007/s10895-015-1557-6

[47] Shellaiah, M., Wu, Y.H. and Lin, H.C. (2013) Simple Pyridyl-Salicylimine-Based Fluorescence "Turn-On" Sensors for Distinct Detections of $\mathrm{Zn}^{2+}, \mathrm{Al}^{3+}$ and $\mathrm{OH}^{-}$Ions in Mixed Aqueous Media. Analyst, 138, 2931-2942. https://doi.org/10.1039/c3an36840h

[48] Chen, C., Wang, R., Guo, L., Fu, N., Dong, H. and Yuan, Y. (2011) A Squaraine-Based Colorimetric and "Turn On" Fluorescent Sensor for Selective Detection of $\mathrm{Hg}^{2+}$ in an Aqueous Medium. Organic Letters, 13, 1162-1165. https://doi.org/10.1021/ol200024g

[49] Li, W., Tian, X., Huang, B., Li, H., Zhao, X., Gao, S., Zheng, J., Zhang, X., Zhou, H., Tian, Y. and Wu, J. (2016) Triphenylamine-Based Schiff Bases as the High Sensitive $\mathrm{Al}^{3+}$ or $\mathrm{Zn}^{2+}$ Fluorescence Turn-On Probe: Mechanism and Application in Vitro and in Vivo. Biosensors and Bioelectronics, 77, 530-536. https://doi.org/10.1016/j.bios.2015.09.059

[50] Kumar, Y.P., King, P. and Prasad, V.S.R.K. (2006) Zinc Biosorption on Tectona grandis L.f. Leaves Biomass: Equilibrium and Kinetic Studies. Chemical Engineering Journal, 124, 63-70. https://doi.org/10.1016/j.cej.2006.07.010 


\section{Supplementary Material}

b<smiles></smiles>

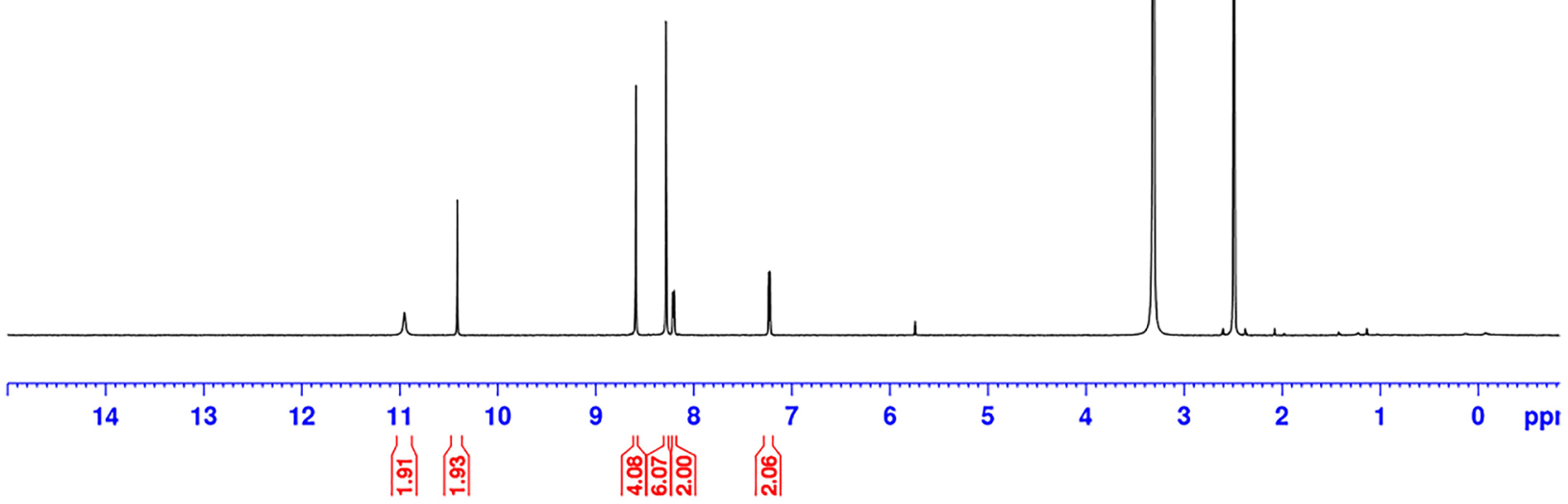

Figure S1. ${ }^{1} \mathrm{H}$ NMR spectrum of 3 .
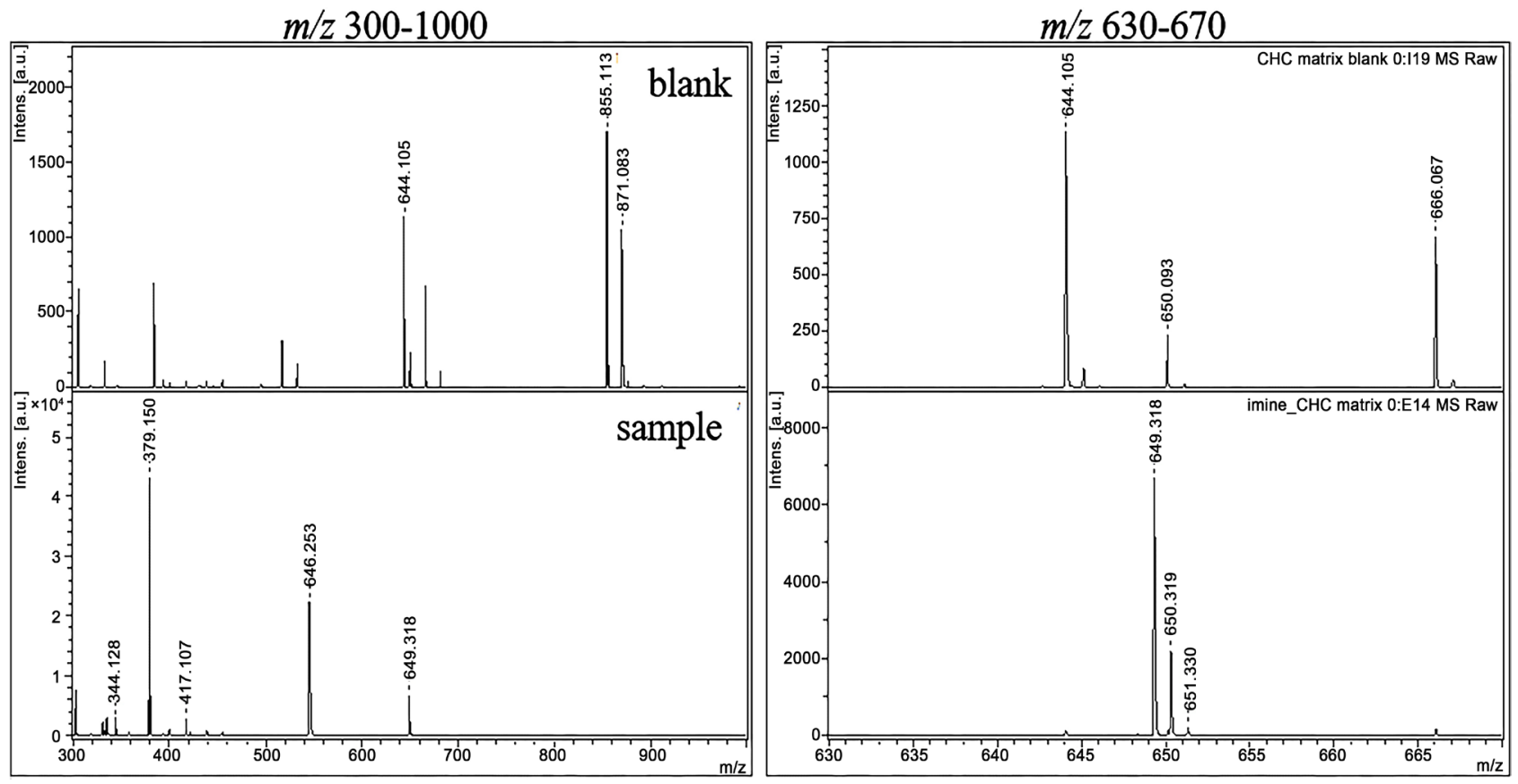

Figure S2. Mass spectra of PySb. 


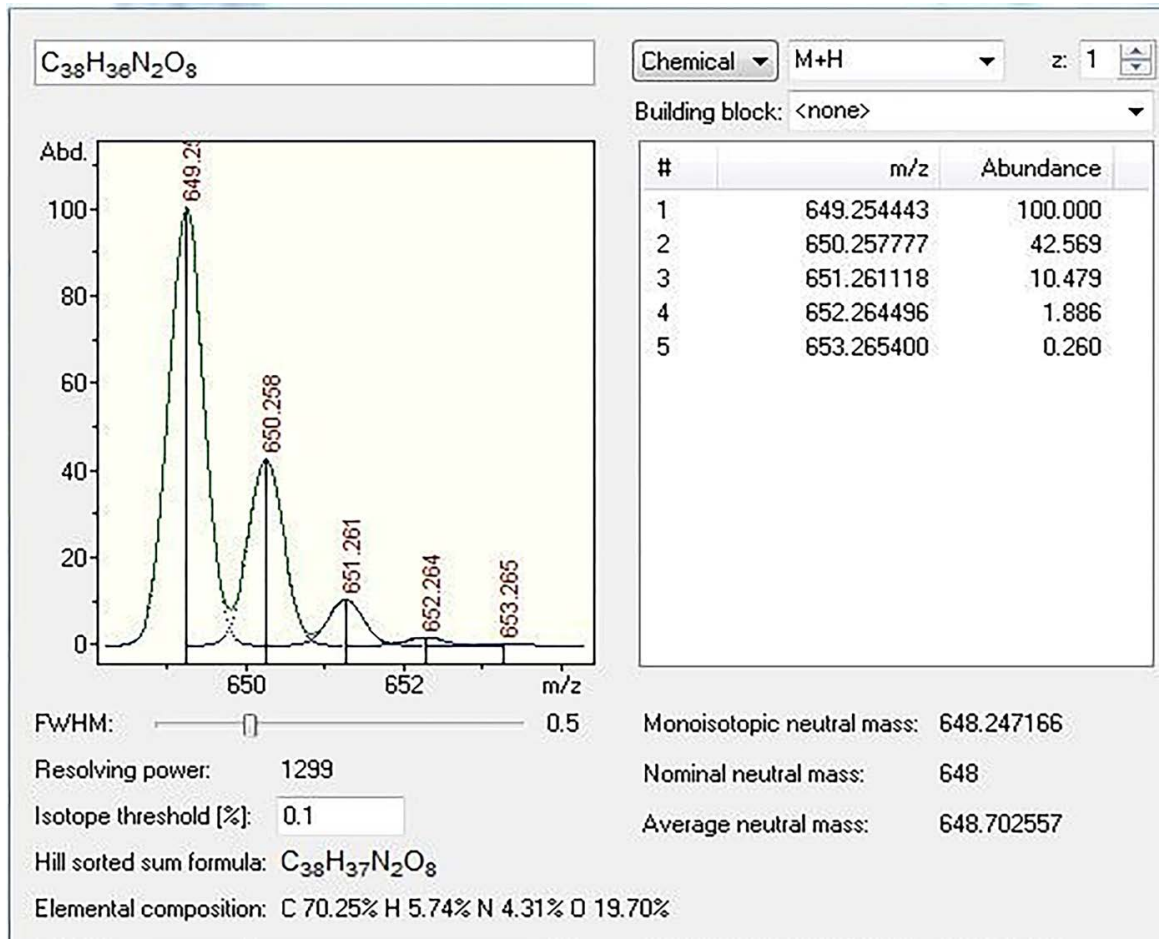

Figure S3. Isotope pattern of PySb.

\section{Binding Constant}

The binding constant can be calculated according to Benesi-Hildebrand equation by measuring the fluorescence intensity change upon addition of various concentrations of $\mathrm{Zn}^{2+}$. The equation is depicted as following [44] [45] [46]:

Assuming 1:2 stoichiometry for association between PySb and $\mathrm{Zn}^{2+}$

$$
\frac{1}{F-F_{0}}=\frac{1}{\Delta F}=\frac{1}{F_{\max }-F_{0}}+\frac{1}{K_{a} \times\left(F_{\max }-F_{0}\right)} \times \frac{1}{\left[\mathrm{Zn}^{2+}\right]^{2}}
$$

$F$ : Observed fluorescence

$F_{0}$ : Fluorescence of free PySb

$F_{\text {max }}:$ Saturated fluorescence of PySb and $\left[\mathrm{Zn}^{2+}\right]$ complex

$K_{a}$ : Binding constant of $\mathrm{PySb}$ and $\left[\mathrm{Zn}^{2+}\right]$

As illustrated in Figure 54 , by plotting $1 / \Delta F$ against $1 /\left[\mathrm{Zn}^{2+}\right]^{2}$, a linear equation can be obtained: $Y=A+B X$. $K_{a}$ was calculated from $A / B$.

$$
K_{a}=\frac{A}{B}=2 \times 10^{9} \mathrm{M}^{-1}
$$

\section{Limit of Detection (LOD)}

Detection limit was calculated based on titration experiment, using the equation as following [47] [48]:

$$
\mathrm{LOD}=\frac{3 \sigma}{m}
$$

$\sigma=$ standard deviation of the blank solution, calculated from 10 blank solutions. 


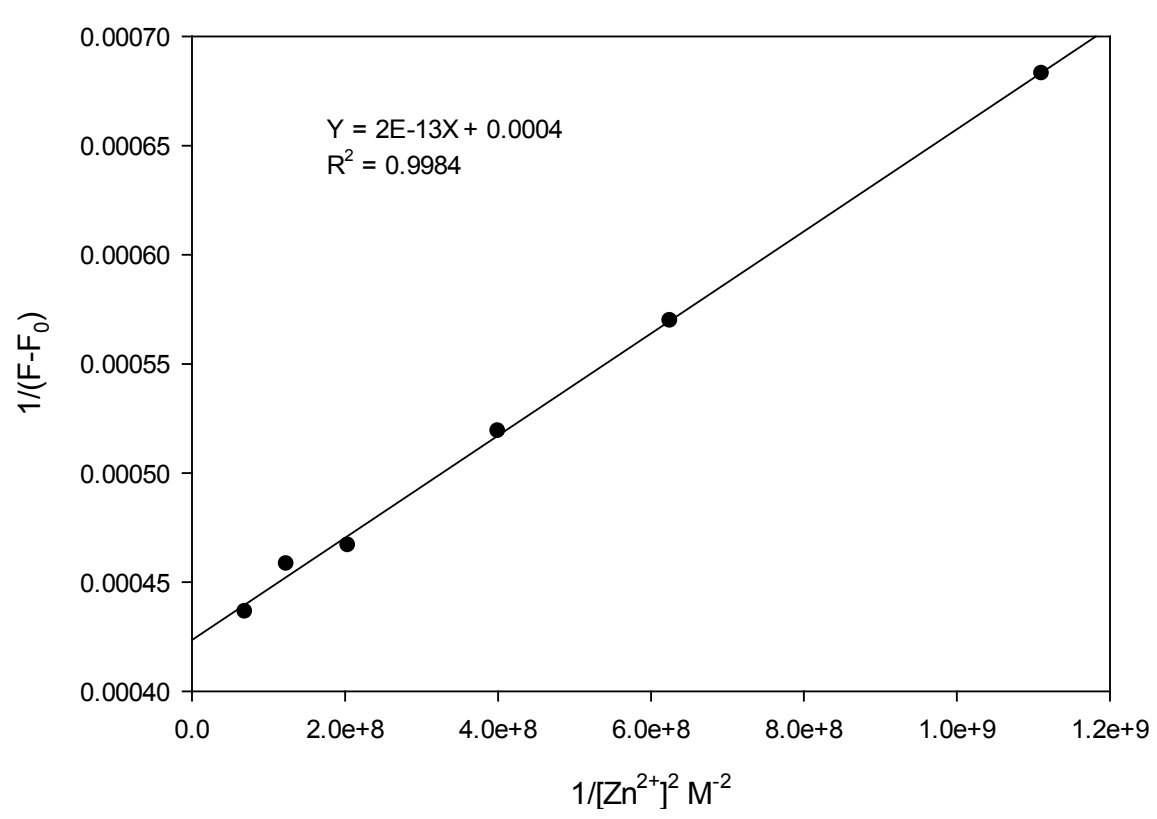

Figure S4. Benesi-Hildebrand plot of PySb, assuming 1:2 stoichiometry for association between PySb and $\mathrm{Zn}^{2+}$ in HEPES buffer solutions (Ethanol/ $\mathrm{H}_{2} \mathrm{O}=9 / 1, \mathrm{v} / \mathrm{v}$ ).

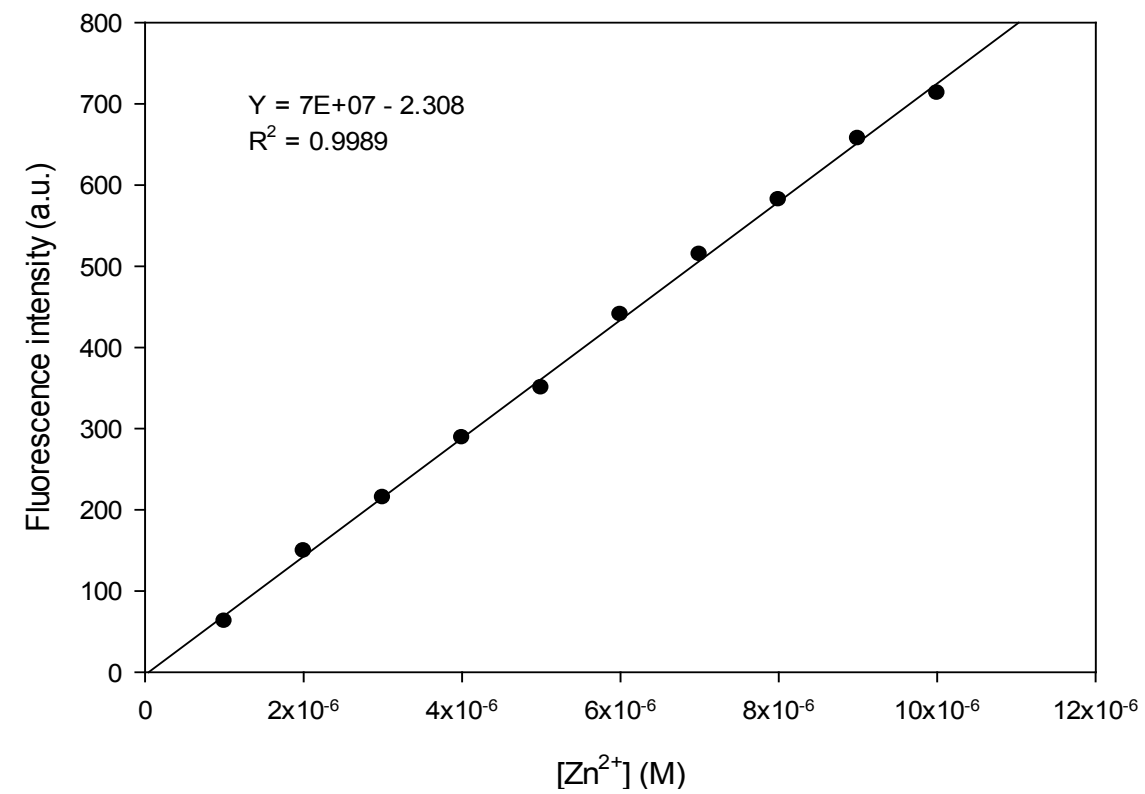

Figure S5. Detection limit of PySb $\left(10^{-5} \mathrm{M}\right)$ toward $\mathrm{Zn}^{2+}$ in HEPES buffer solutions (Ethanol/ $\left.\mathrm{H}_{2} \mathrm{O}=9 / 1, \mathrm{v} / \mathrm{v}\right)$.

$m=$ slope of fluorescence intensity versus $\mathrm{Zn}^{2+}$ concentration.

$$
\begin{gathered}
\sigma=0.558 \\
\mathrm{LOD}=\frac{3 \times 0.558}{7 \times 10^{7}}=2.39 \times 10^{-8} \mathrm{M}
\end{gathered}
$$

The detection limit of PySb toward $\mathrm{Zn}^{2+}$ was $2.39 \times 10^{-8} \mathrm{M}$, which is much higher than the World Health Organization guideline for maximum acceptable concentration in drinking water: $76 \mu \mathrm{M}$ [49] [50]. 